\title{
Relative Efficacy of Different Exercises for Pain, Function, Performance and Quality of Life in Knee and Hip Osteoarthritis: Systematic Review and Network Meta-Analysis
}

\author{
Siew-Li Goh ${ }^{1,2}$ (1) Monica S. M. Persson ${ }^{1}$. Joanne Stocks ${ }^{1} \cdot$ Yunfei Hou ${ }^{3} \cdot$ Nicky J. Welton ${ }^{4}$ Jianhao Lin ${ }^{3}$. \\ Michelle C. Hall ${ }^{5}$. Michael Doherty ${ }^{1} \cdot$ Weiya Zhang $^{1}$
}

Published online: 4 March 2019

(c) The Author(s) 2019

\begin{abstract}
Background Guidelines recommend exercise as a core treatment for osteoarthritis (OA). However, it is unclear which type of exercise is most effective, leading to inconsistency between different recommendations.

Objectives The aim of this systematic review and network meta-analysis was to investigate the relative efficacy of different exercises (aerobic, mind-body, strengthening, flexibility/skill, or mixed) for improving pain, function, performance and quality of life (QoL) for knee and hip OA at, or nearest to, 8 weeks.

Methods We searched nine electronic databases up until December 2017 for randomised controlled trials that compared exercise with usual care or with another exercise type. Bayesian network meta-analysis was used to estimate the relative effect size (ES) and corresponding 95\% credibility interval (CrI) (PROSPERO registration: CRD42016033865).

Findings We identified and analysed 103 trials (9134 participants). Aerobic exercise was most beneficial for pain (ES 1.11; $95 \% \mathrm{CrI} 0.69,1.54)$ and performance $(1.05 ; 0.63,1.48)$. Mind-body exercise, which had pain benefit equivalent to that of aerobic exercise $(1.11 ; 0.63,1.59)$, was the best for function $(0.81 ; 0.27,1.36)$. Strengthening and flexibility/skill exercises improved multiple outcomes at a moderate level. Mixed exercise was the least effective for all outcomes and had significantly less pain relief than aerobic and mind-body exercises. The trend was significant for pain $(p=0.01)$, but not for function $(p=0.07)$, performance $(p=0.06)$ or QoL $(p=0.65)$.

Conclusion The effect of exercise varies according to the type of exercise and target outcome. Aerobic or mind-body exercise may be the best for pain and function improvements. Strengthening and flexibility/skill exercises may be used for multiple outcomes. Mixed exercise is the least effective and the reason for this merits further investigation.
\end{abstract}

Electronic supplementary material The online version of this article (https://doi.org/10.1007/s40279-019-01082-0) contains supplementary material, which is available to authorized users.

Weiya Zhang

Weiya.Zhang@nottingham.ac.uk

1 Arthritis Research UK Pain Centre, Academic Rheumatology, University of Nottingham, Clinical Sciences Building, City Hospital, Nottingham NG5 1PB, UK

2 Sports Medicine Unit, University of Malaya, Kuala Lumpur, Malaysia

3 Department of Orthopaedic Surgery, Peking University People's Hospital, Beijing, China

4 Population Health Sciences, University of Bristol, Bristol, UK

5 Division of Physiotherapy Rehabilitation Sciences Education, University of Nottingham, Nottingham, UK

\section{Key Points}

The effect of exercise in knee and hip osteoarthritis depends on type of exercise and outcome of interest.

Aerobic and mind-body exercises appear to be the two most effective exercise therapies for pain and function, whereas strengthening and flexibility exercises appear to be good for moderate improvement of multiple outcomes.

Mixed exercise is the least effective exercise. However, it may be used for patients who do not respond to other types of exercise therapy because it is still better than no exercise control for all four patient-centred outcomes. 


\section{Introduction}

Pain from knee and hip osteoarthritis (OA) can have a significant impact on the physical function and quality of life (QoL) of affected individuals worldwide [1]. Exercise is one of the core therapies for OA [2] to improve pain and function $[3,4]$. Existing evidence indicates that the magnitude of response varies according to the type of exercise (e.g. strengthening, aerobic etc.) [5]. However, little is known about the relative efficacy between different exercises for different outcomes.

Most randomised controlled trials (RCTs) compare exercise regimens against non-exercise interventions, and direct comparisons between different exercises are uncommon. This is because a head-to-head comparison trial is very costly and it is impractical to undertake RCTs to examine the relative effects between all types of exercises. Alternatively, network meta-analysis (NMA) can indirectly compare multiple interventions through a common comparator when head-to-head RCTs are sparse or absent [6]. It utilises all available evidence in the network, both direct and indirect, to enhance the power of the estimation [7].

Previously, Uthman et al. [8] undertook a sequential analysis and NMA to examine whether there was sufficient evidence to support the use of exercise for people with lower limb OA, and whether one exercise was better than another. They found that up to 2002, sufficient evidence existed to show a significant benefit of exercise over no exercise. Strengthening exercise yielded the largest effect size for pain outcomes, whereas a combined intervention of strengthening, flexibility and aerobic exercise had the largest effect size for function. However, no performance or QoL measures were included.

In this review, we aimed to extend the work of Uthman et al. [8] by updating the evidence, expanding the outcomes to include objective performance measures and QoL, and refining the exercise classification to include mind-body exercise such as tai chi and yoga.

\section{Methods}

\subsection{Search Strategy and Selection Criteria}

This NMA is part of a larger review that included RCTs comparing all forms of exercise to non-exercise interventions, or to another exercise type. Detailed inclusion criteria for the larger review are available in our registered and published protocol (PROSPERO CRD42016033865) [9]. The specific inclusion criteria for this NMA were RCTs that (1) recruited participants with knee OA, hip OA, or mixed knee and hip OA diagnosed clinically and/or radiographically;
(2) assigned exercise programmes without additional active treatment (e.g. analgesics) as the intervention; (3) assigned usual care/waiting list or a different exercise as the control group; and (4) measured at least one outcome for pain, function, objective performance or QoL.

The systematic search was conducted in December 2015 and updated in December 2017. Nine electronic databases (Allied and Complementary Medicine Database (AMED), Cochrane Central Register of Controlled Trials (CENTRAL), Cumulative Index to Nursing and Allied Health Literature (CINAHL), Excerpta Medica Database (EMBASE), MEDLINE Ovid, Physiotherapy Evidence Database (PEDro), PubMed, SPORTDiscus and Google Scholar) were searched for peer-reviewed publications without language or publication date limitations. As an example, the Medline search strategy is shown in Electronic Supplementary Material (ESM) Appendix 1. The reference lists of systematic review protocols published in Cochrane Library since 2014 were used to supplement the electronic database search. Publication of study protocols were flagged pending the full publication of the trials.

Selection of relevant studies and subsequent data extraction was undertaken by a single reviewer (SLG), with advice from a second reviewer (MH) should queries arise. A third reviewer (WZ) was involved if agreement could not be reached. Data extraction was compared between SLG and either MSMP, JS or YFH in a random sample (10\%) of selected studies. Should disagreement be over $5 \%$ of the total extracted variables, the whole set of the studies would be double extracted, otherwise the single extraction was used; that is, a maximum 5\% disagreement was allowed for data extraction.

\subsection{Interventions}

Exercises were classified into muscle strengthening, aerobic, or flexibility/neuro-motor skills training (flexibility/ skill) according to the American College of Sports Medicine (ACSM) recommendation [10]. Strengthening exercises are exercises that aim to increase force of muscle contraction (e.g. lifting dumbbells, squats); aerobic exercises to improve cardiorespiratory endurance (e.g. swimming, jogging); flexibility exercises to improve joint range of motion and muscle pliability (e.g. hamstring stretch, gastrocnemius stretch); and neuromotor skills training to improve balance and coordination (e.g. wobble board, walking on foam). In addition, an exercise programme was classified as mind-body exercise if it integrated mindfulness/relaxation into physical movements (e.g. tai chi, yoga), and classified as mixed exercise when it included more than one core exercise type mentioned above, or when the authors did not specify it as a single component exercise. 
'Usual care' control was determined based on the report. In 'usual care', participants were expected to continue the routine standard of care provided by their general practitioners. Control groups that were not given any specific intervention such as 'waiting list' or usual physical activity or where the authors did not specify the nature of the control were also classified as 'usual care'. 'Waiting-list' controls were given active intervention after a period of observation, with no new intervention being delivered during the trial period.

\subsection{Outcomes}

Our primary outcome of interest was pain, and secondary outcomes were self-reported function, objective performance (e.g. walking speed, strength, range of motion), and QoL. The primary time point was 8 weeks after commencement of the exercise regimen or the time point nearest to this. Eight weeks was chosen because it was the most frequently reported time point. When more than one scale was presented for pain, function or QoL, the more comprehensively reported scale was selected in the ranking order proposed by Fransen and McConnell [4] and Regnaux et al. [11].

For the performance, gait and walking parameters (e.g. walking distance, walking time, etc.) were prioritised. This was because the measurement and reporting of these parameters were relatively standard across trials compared with other performance outcomes such as strength or power. Limb-specific parameters, such as strength, power, or range of motion were only used if gait parameters were not available. Strength parameters extracted were, in descending order of preference, knee extensors, knee flexors, hip abductors, and then other muscle groups. When tests performed at varying intensities were reported, the results from the highest intensity tests were chosen.

\subsection{Data Analysis}

The standardised mean difference of the change score (end-point minus baseline score) was used to estimate the effect size (ES). Standard deviations (SD) were imputed for trials that did not provide the SD or did not provide sufficient information to calculate the SD. The missing SD was imputed using the largest SD of the same scale reported in other trials if available, otherwise an arithmetic mean of other SDs was used [12].

A Bayesian random effects NMA model for continuous outcome data was used for the primary analysis. The WinBUGS codes were adapted from Dias et al. [13] and are provided in ESM Appendix 2. The posterior mean of the ES was reported with its $95 \%$ credibility intervals (CrI). Bayesian NMA produces simulations that allow interventions to be ranked from first to sixth. The median ranking and corresponding 95\% CrI was generated alongside the pooled
ES to identify the most effective exercise choice [14]. The significance of the ES hierarchical trend was assessed using meta-regression analysis [15].

Non-informative prior distributions were used and three Markov chains were run simultaneously. The initial 40,000 simulations were discarded as the burn-in period and the subsequent 120,000 simulations were used. Inspection of Gelman-Rubin tracing was performed to ensure that convergence or stabilisation of the simulations had been achieved.

Model fit, a measure of how well predictions from the model were supported by the observed data, was assessed. Consistency in the network was assessed by the node-splitting method [16] and design by treatment forest plot [17] based on frequentist analysis. The node-splitting method examines the agreement between direct and indirect comparisons. Design by treatment forest plot, on the other hand, visually demonstrates agreement between studies of different designs (e.g. whether estimation between $\mathrm{A}$ and $\mathrm{C}$, obtained from two-arm design, is consistent with those obtained from multi-arm ABC or ACD designs). Data were processed and analysed using Microsoft Access, Excel, Stata (StataCorp. 2017. Stata Statistical Software: Release 15. College Station, TX, USA: StataCorp LLC), and WinBUGS (Version 1.4.3).

\subsection{Sensitivity Analysis and Subgroup Analysis}

A modified Cochrane risk of bias assessment tool was used to assess study quality. Sensitivity analyses were performed on two of the items with the highest risk of bias and also on studies for which SD had been imputed. Subgroup analyses were performed to assess the efficacy at different joints (knee OA versus hip OA) and for different patient contexts, such as participants awaiting total joint replacement (TJR) versus participants not awaiting TJR.

\section{Results}

From the initial 13,596 citations retrieved from the databases and 76 hand searches, we identified 239 articles (217 trials) to be eligible under the broader search strategy that included all types of non-exercise comparators including other nonpharmacological therapies or drugs (Fig. 1). Since the present NMA only considered trials comparing the five defined exercises with usual care or each other, only 103 trials (9134 participants) were included [18-130]. Of these, 76 (74\%) trials used usual care as the control and 27 were head-to-head comparisons. Disagreement for double extraction of data was within the acceptable limit, so predominantly single extraction was retained. The characteristics of the included trials are listed in Table 1. Pain was assessed in 89 trials (7184 participants), function in 87 trials (7153 participants), performance in 95 trials (6760 participants), and QoL in 


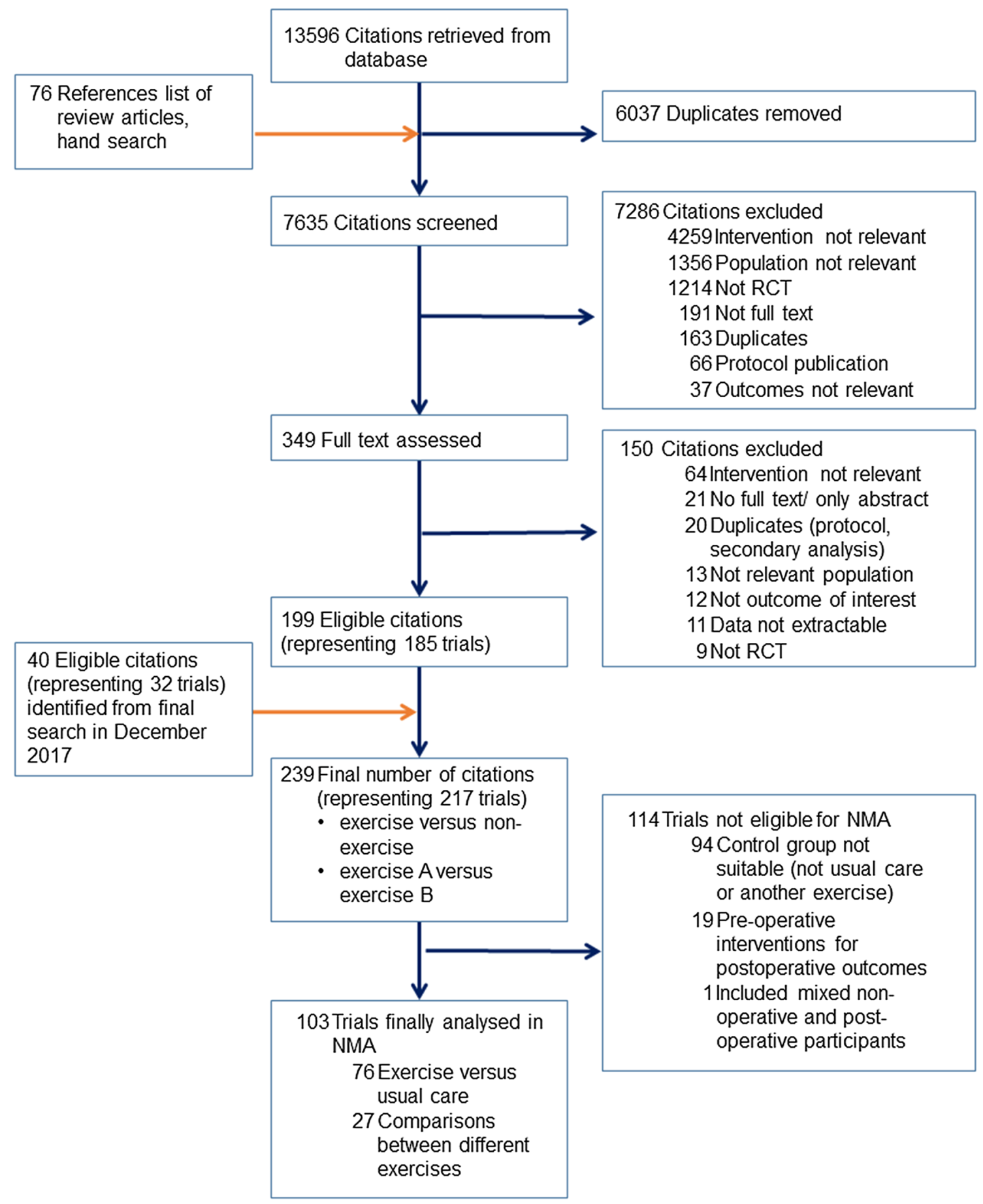

Fig. 1 Study flow diagram for comparison between exercise and usual care and between different exercises. NMA network meta-analysis, $R C T$ randomised controlled trials

40 trials (3190 participants) (Table 2). Preliminary assessment of funnel plots identified one outlying study for pain [112] and another for QoL [48]. Both studies showed strong positive effects $(E S>5)$, very different from other studies. These studies were subsequently excluded from the main analysis. Egger's statistical test is suggestive of publication bias $(p<0.05)$ for all outcomes except QoL (ESM Appendix 3). Figure 2 demonstrates the network for pain, function, performance and QoL. The comparisons were most seen between strengthening versus usual care, as well as between mixed exercise versus usual care. 


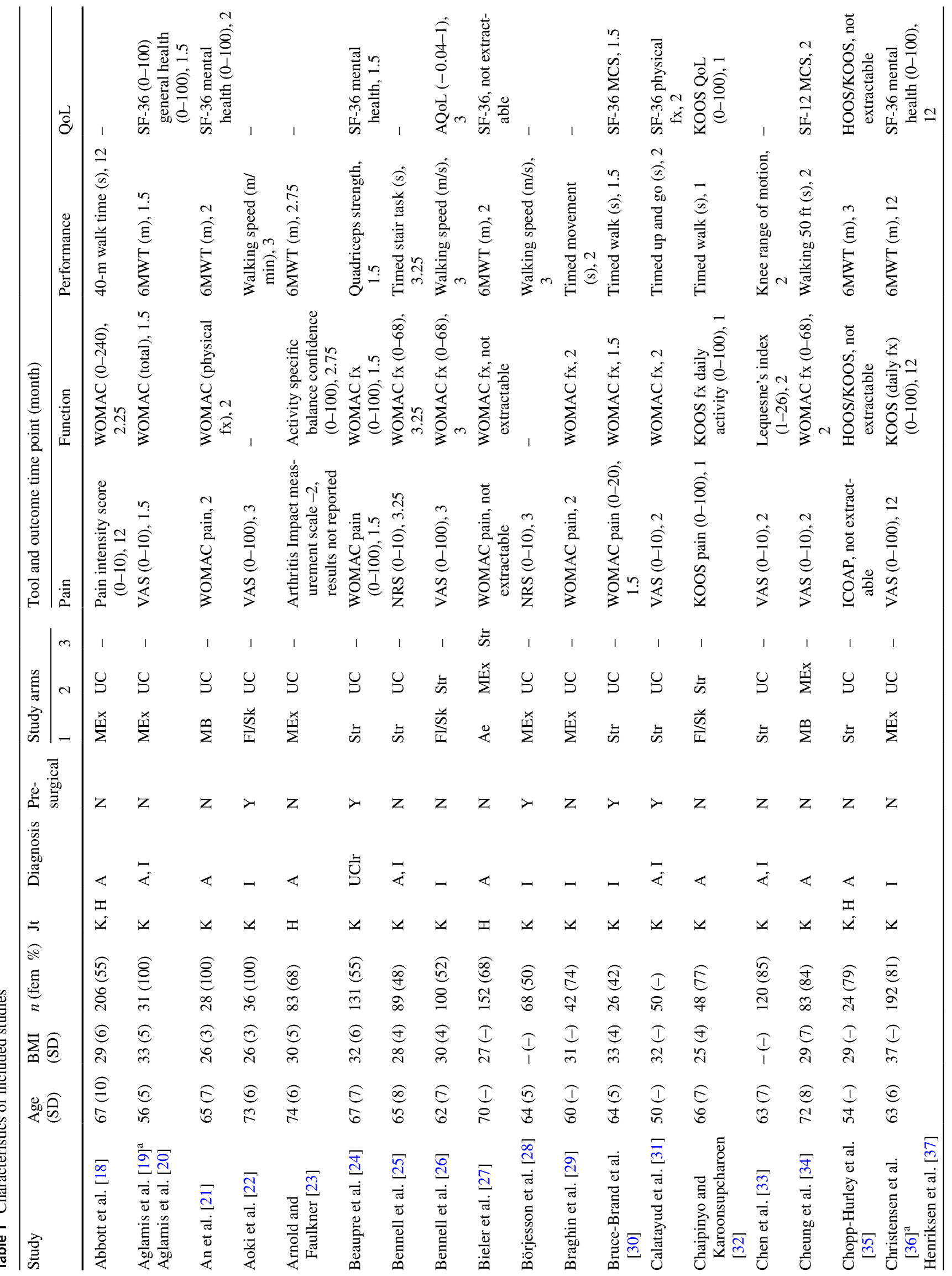




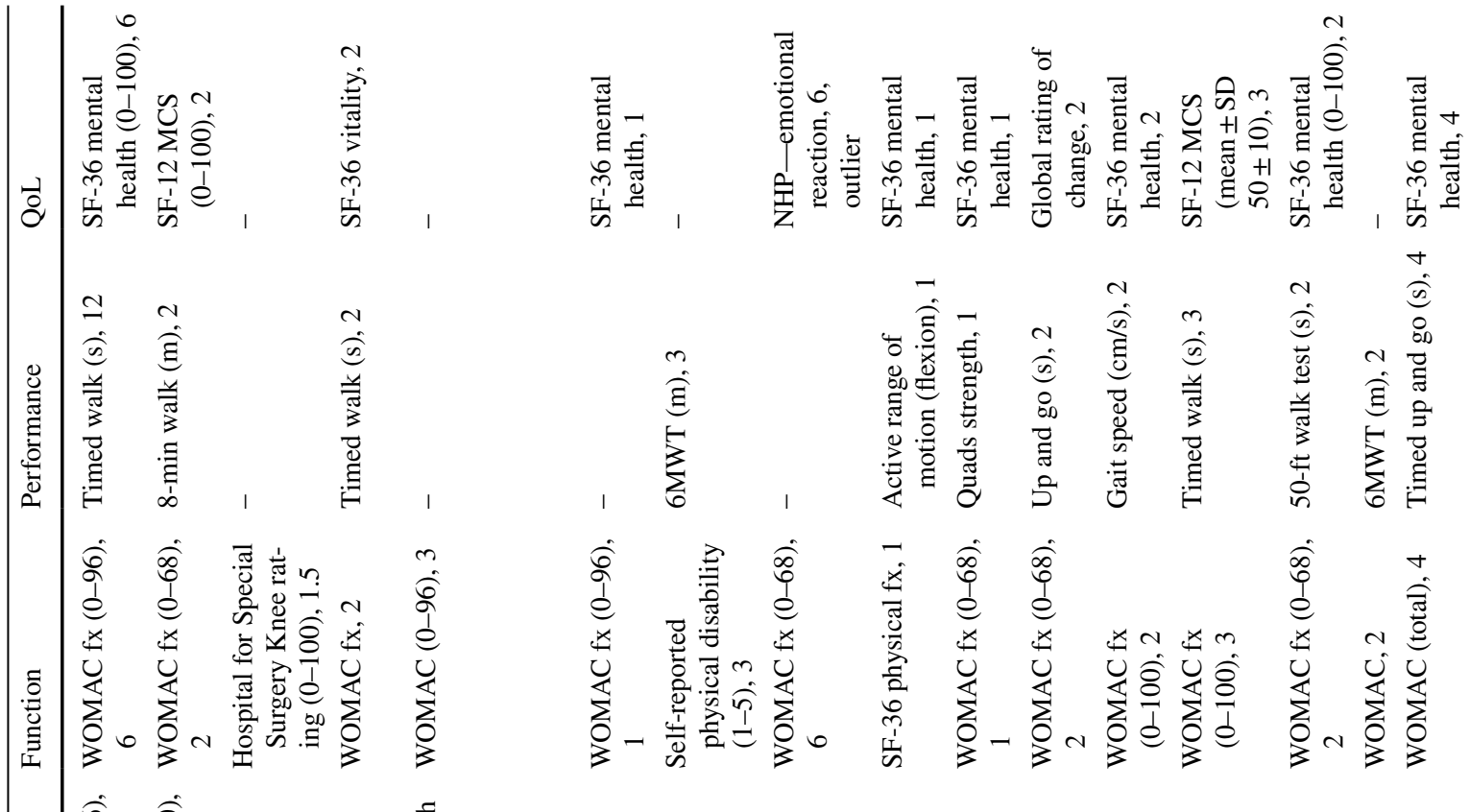

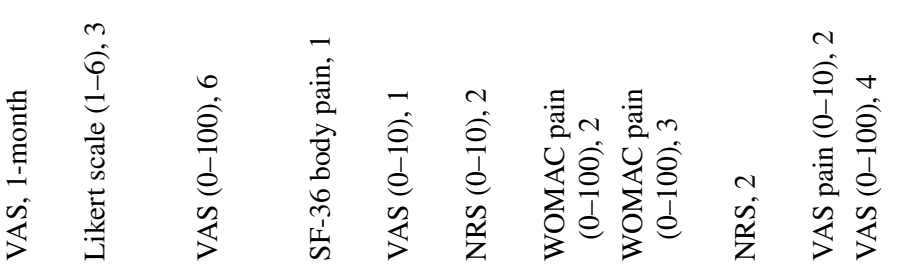
ए

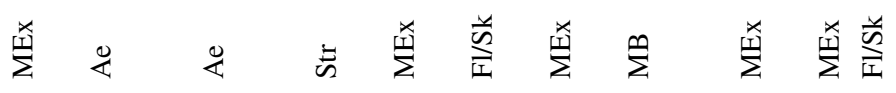




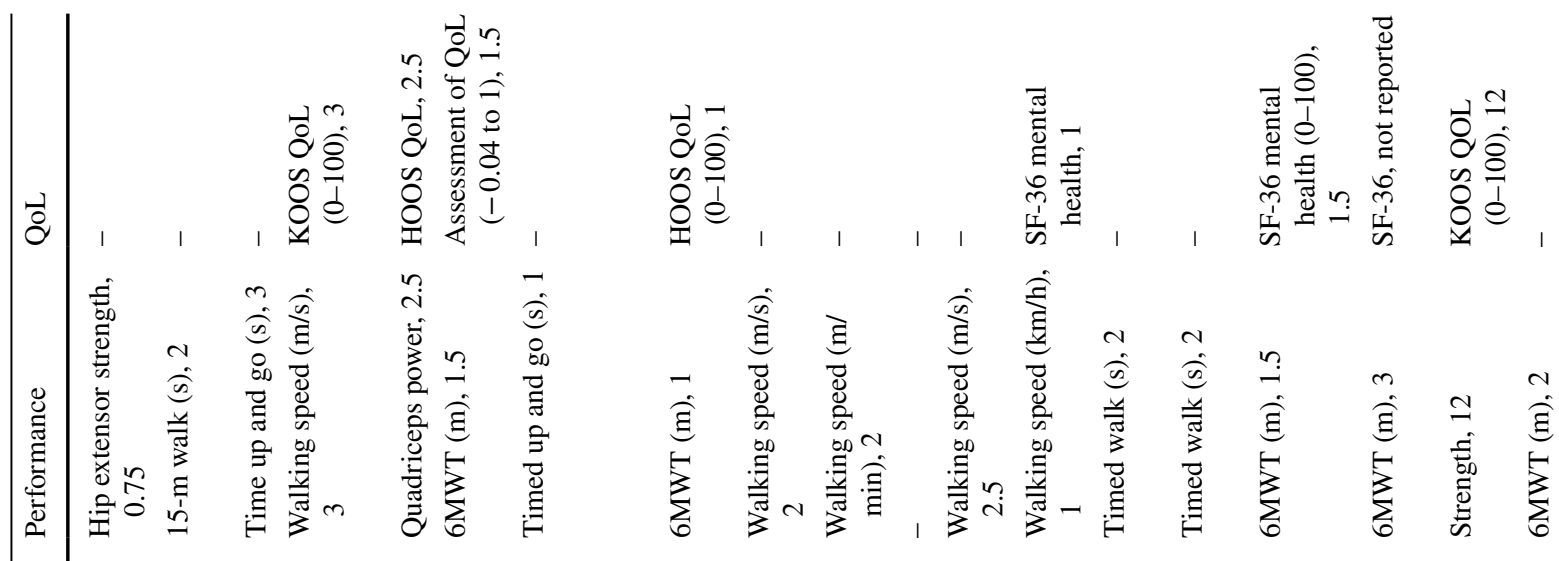

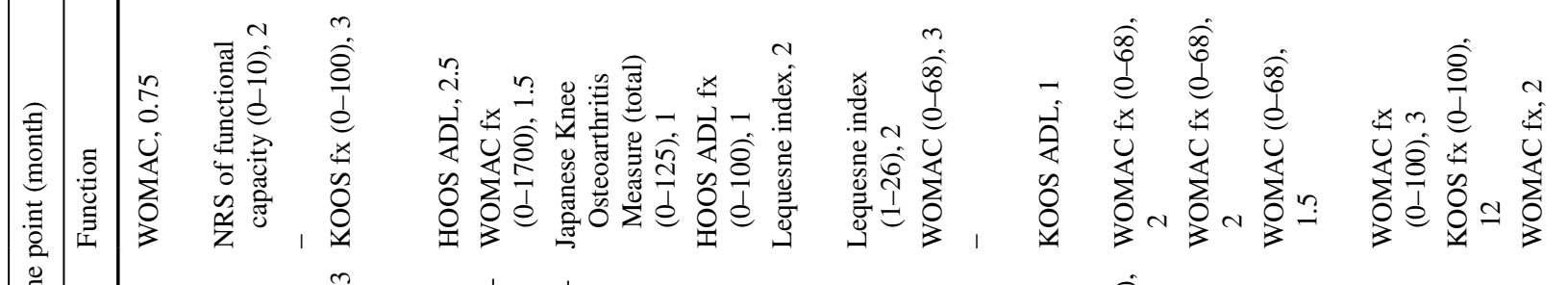

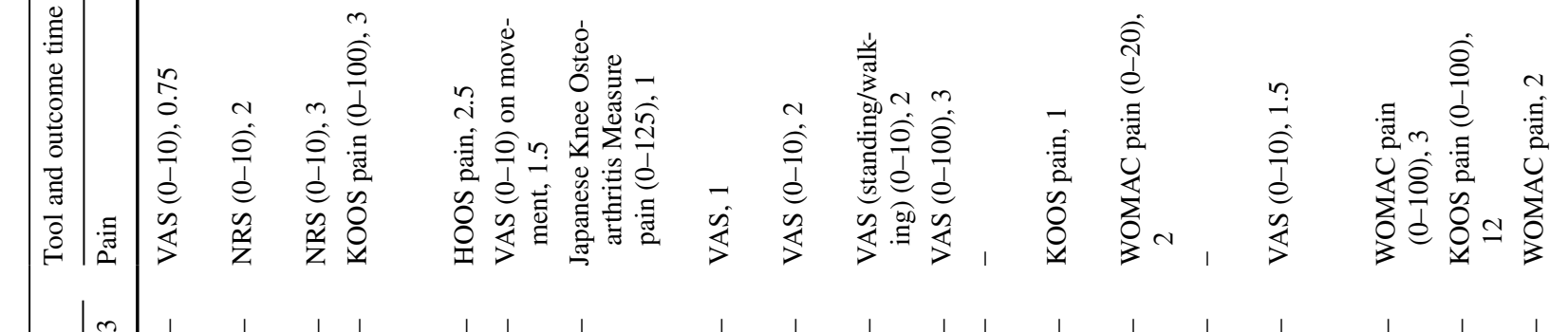

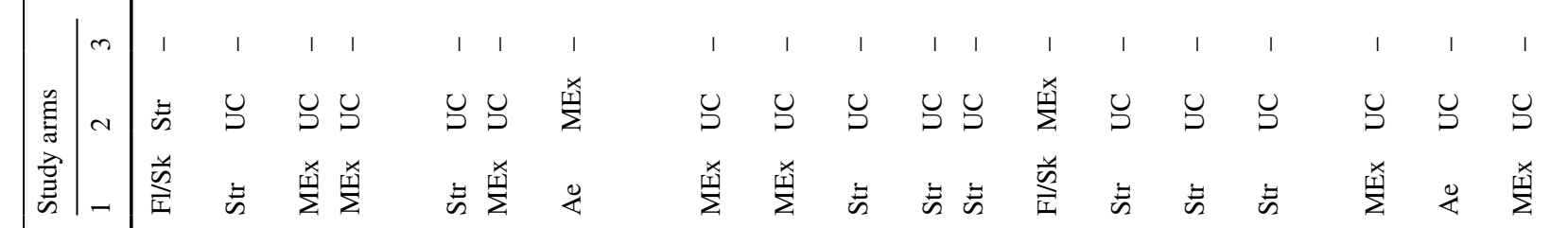

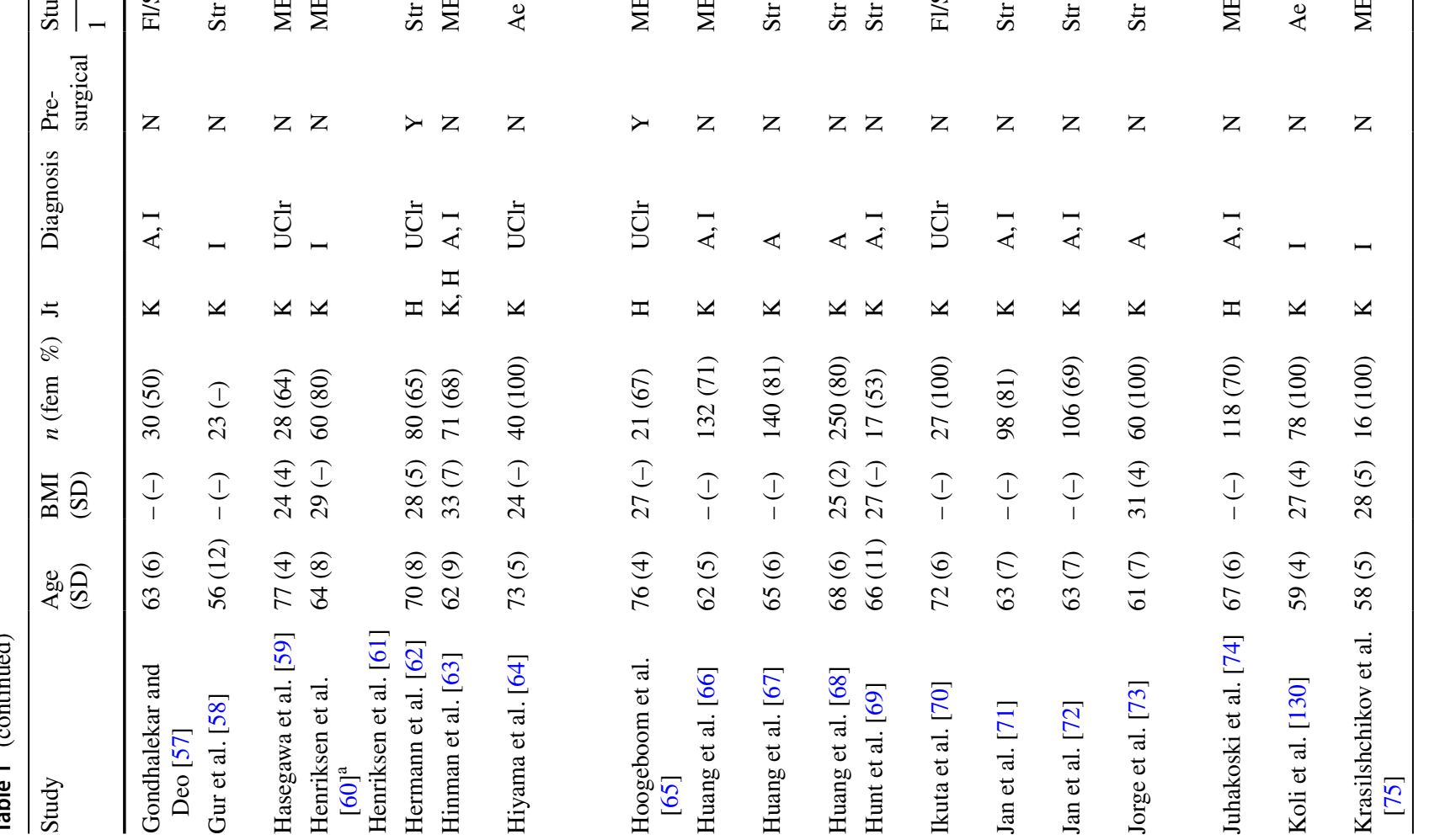




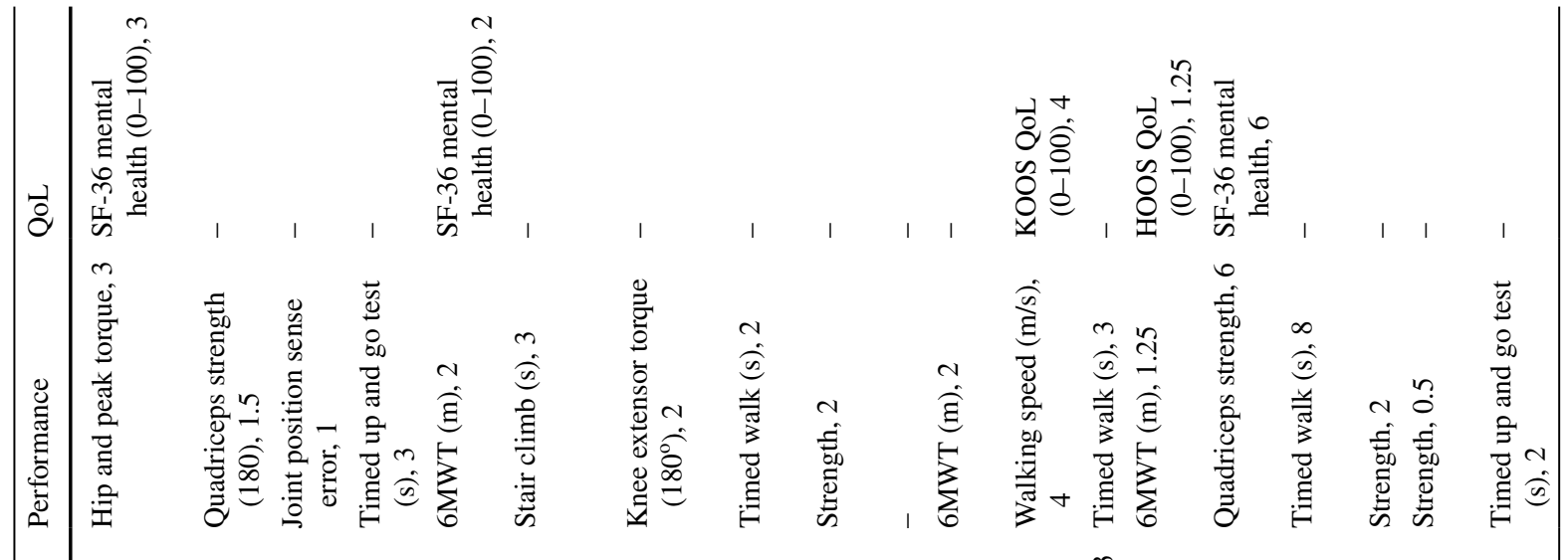

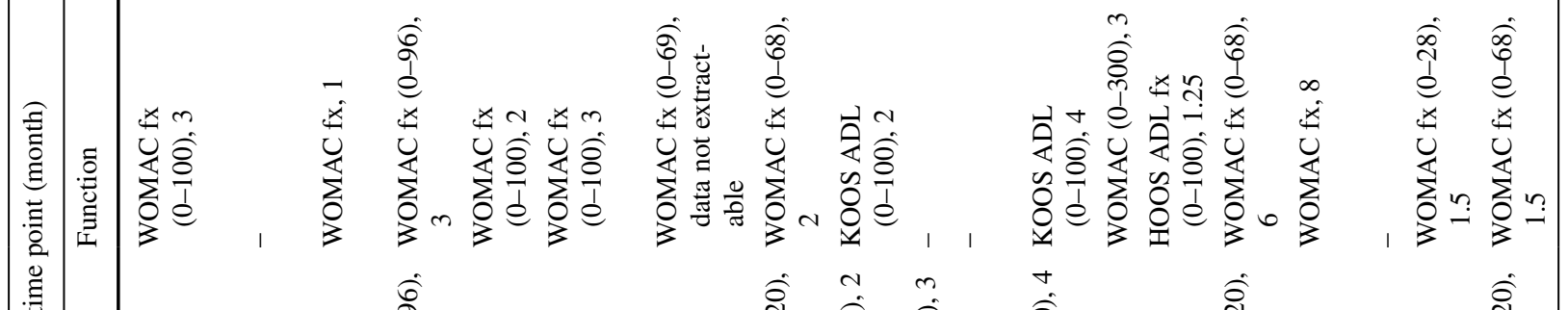

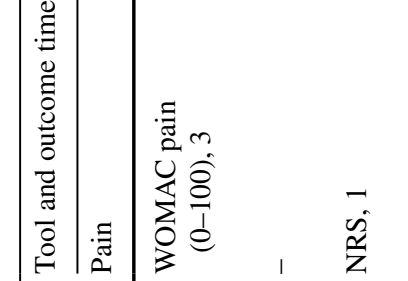

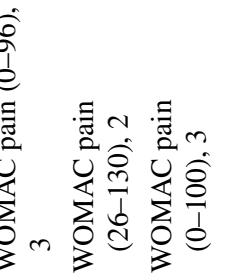

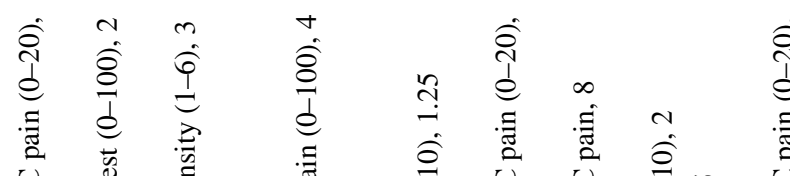

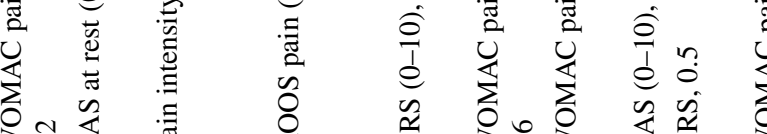

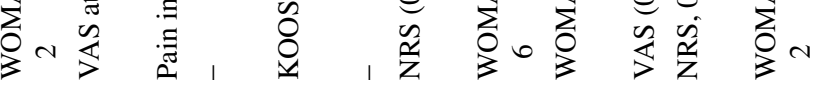

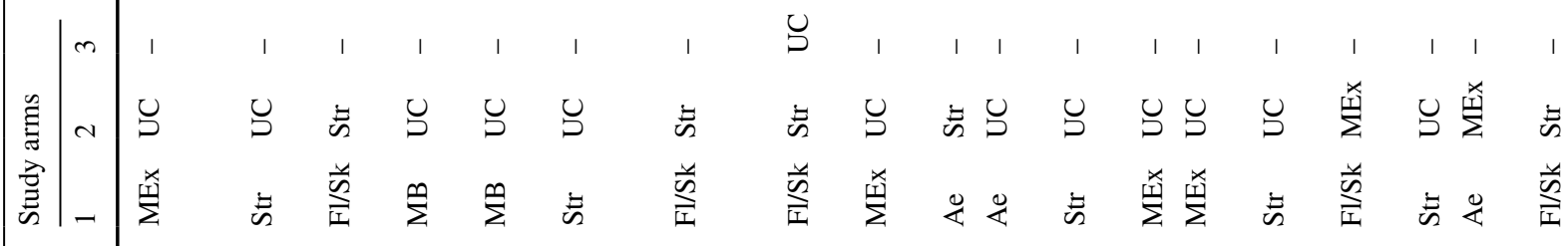

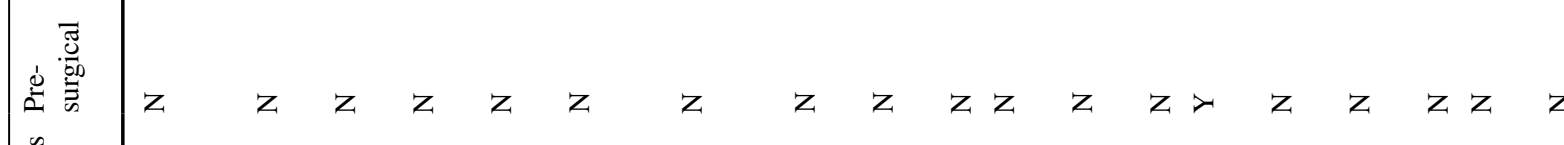

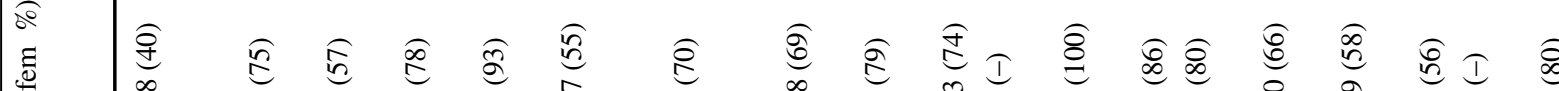

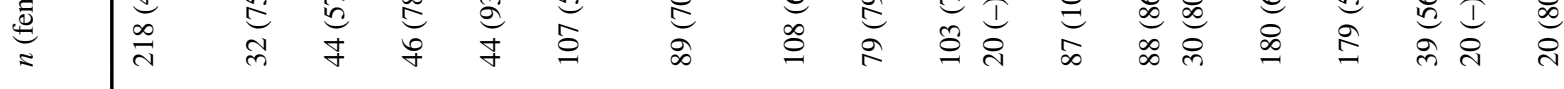

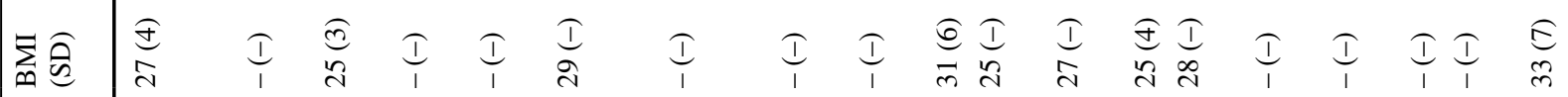

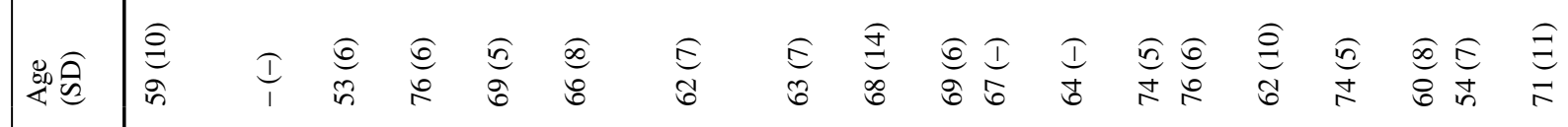
(a)

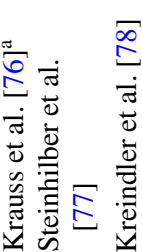

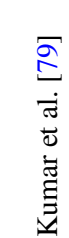

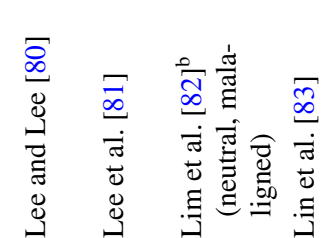

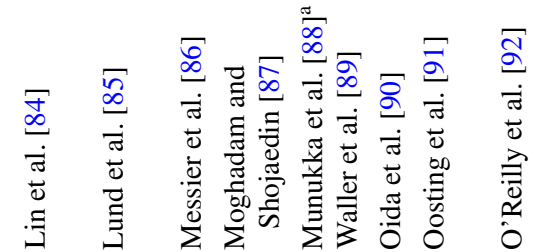

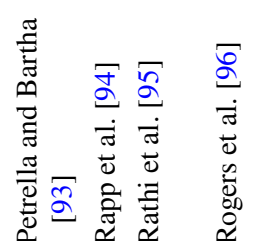




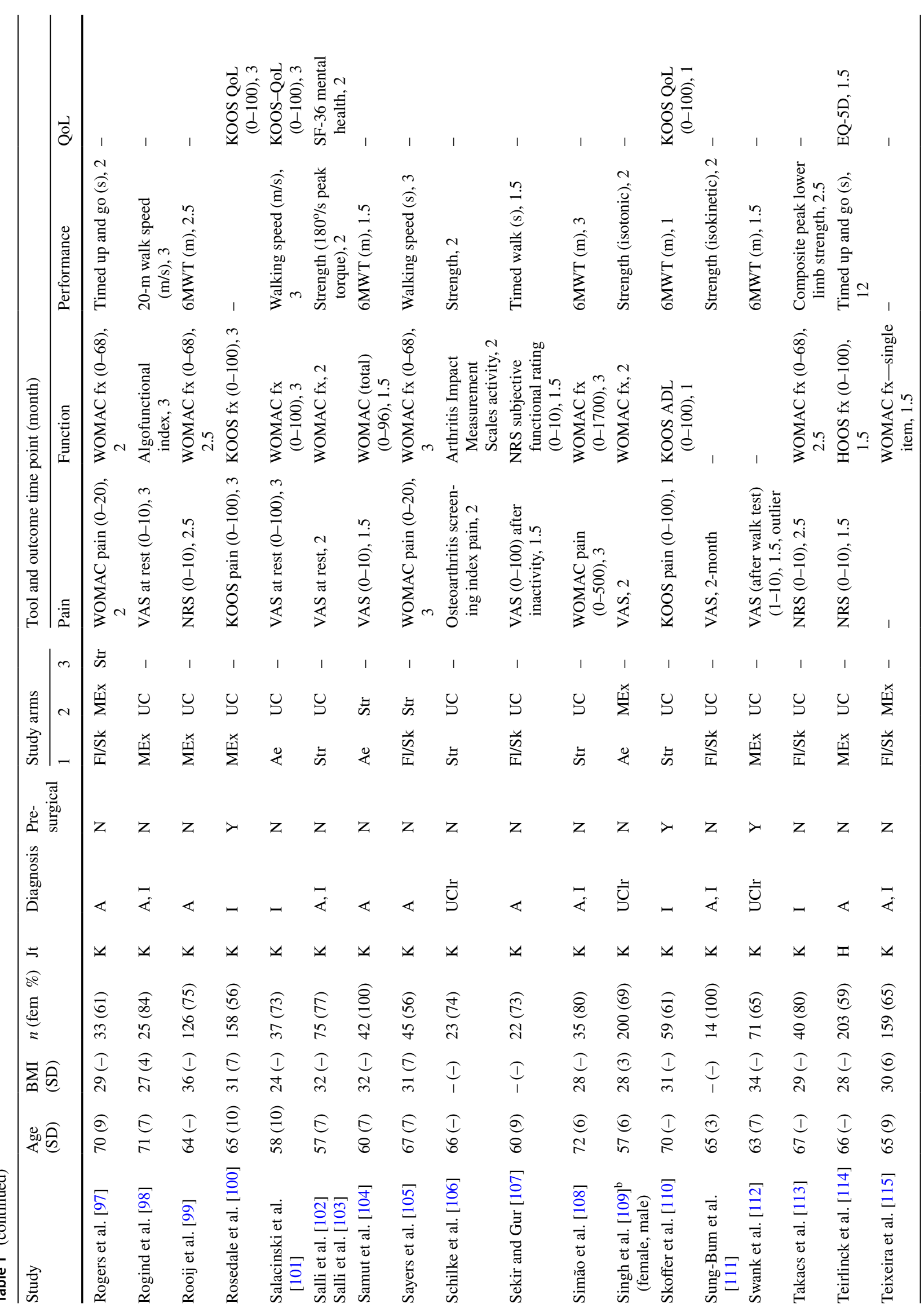




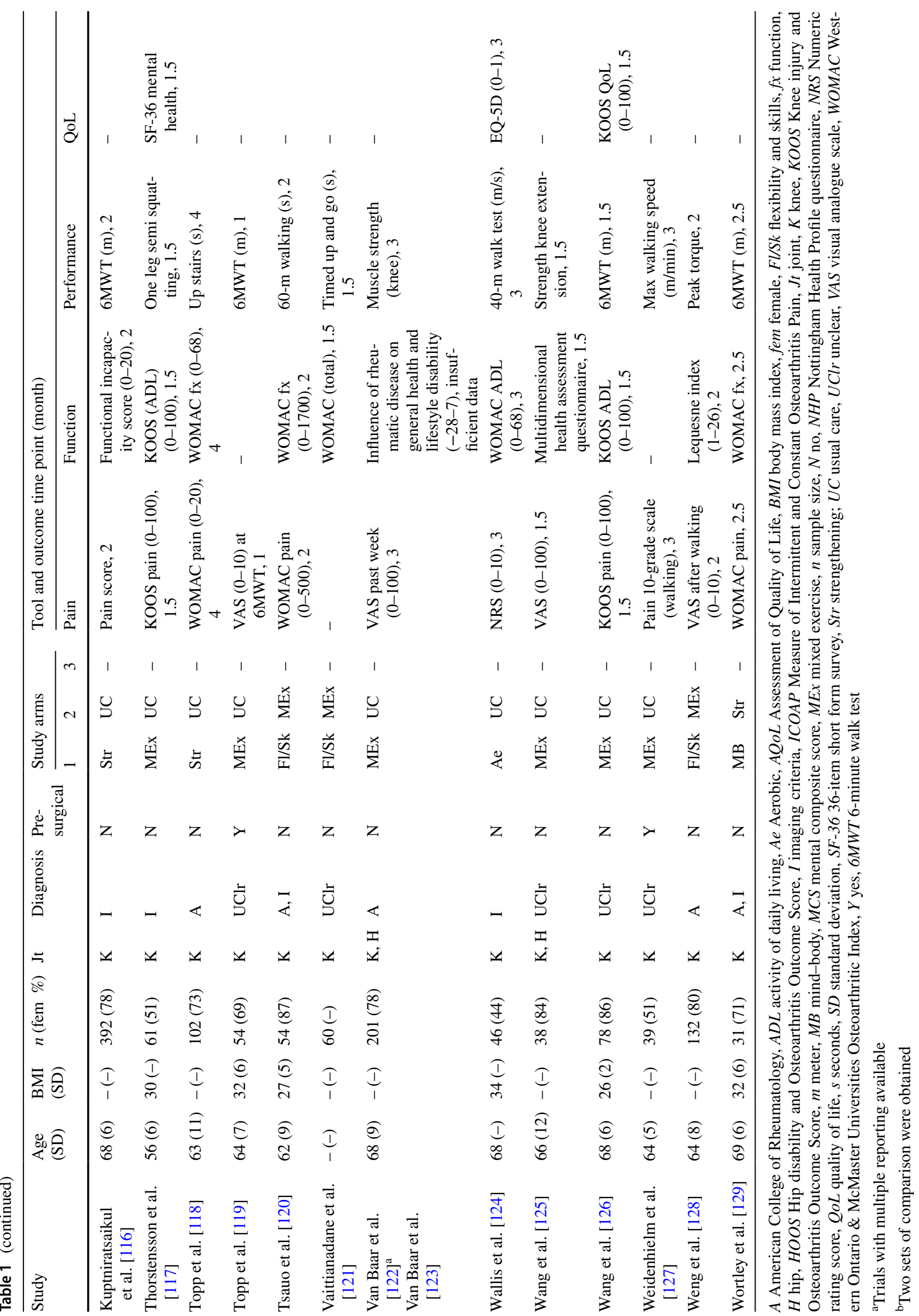


Table 2 Characteristics of studies by outcomes

\begin{tabular}{lllll}
\hline & Pain & Function & Performance & QoL \\
\hline No. of comparisons & 97 & 97 & 105 & 42 \\
Versus usual care & 70 & 67 & 74 & 34 \\
Versus another exercise & 27 & 30 & 31 & 8 \\
No. of trials (no. participants) & $89(7184)$ & $87(7153)$ & $95(6760)$ & $40(3190)$ \\
Knee & $75(5607)$ & $73(5733)$ & $78(5156)$ & $30(2073)$ \\
Hip & $8(703)$ & $9(754)$ & $10(905)$ & $7(585)$ \\
Both & $6(874)$ & $5(666)$ & $7(699)$ & $3(532)$ \\
Age, median (IQR), years & $64.9(62.0-68.7)$ & $64.9(62.0-69.1)$ & $65.1(62.4-69.8)$ & $65.3(62.0-69.7)$ \\
BMI, median (IQR), kg/m ${ }^{2}$ & $29.0(27.1-31.5)$ & $29.4(27.2-31.5)$ & $29.0(27.1-31.5)$ & $29.5(27.1-31.5)$ \\
Female, median (IQR), \% & $73.0(61.0-80.7)$ & $73.4(62.8-81.0)$ & $73.0(64.1-81.0)$ & $73.7(61.0-93.2)$ \\
Study design & & & & 39 \\
2 arms & 86 & 83 & 91 & 1 \\
3 arms & 3 & 4 & 4 & \\
\hline
\end{tabular}

Data presented for each outcome excludes outliers and un-extractable data $B M I$ body mass index, $I Q R$ interquartile range, $Q o L$ quality of life
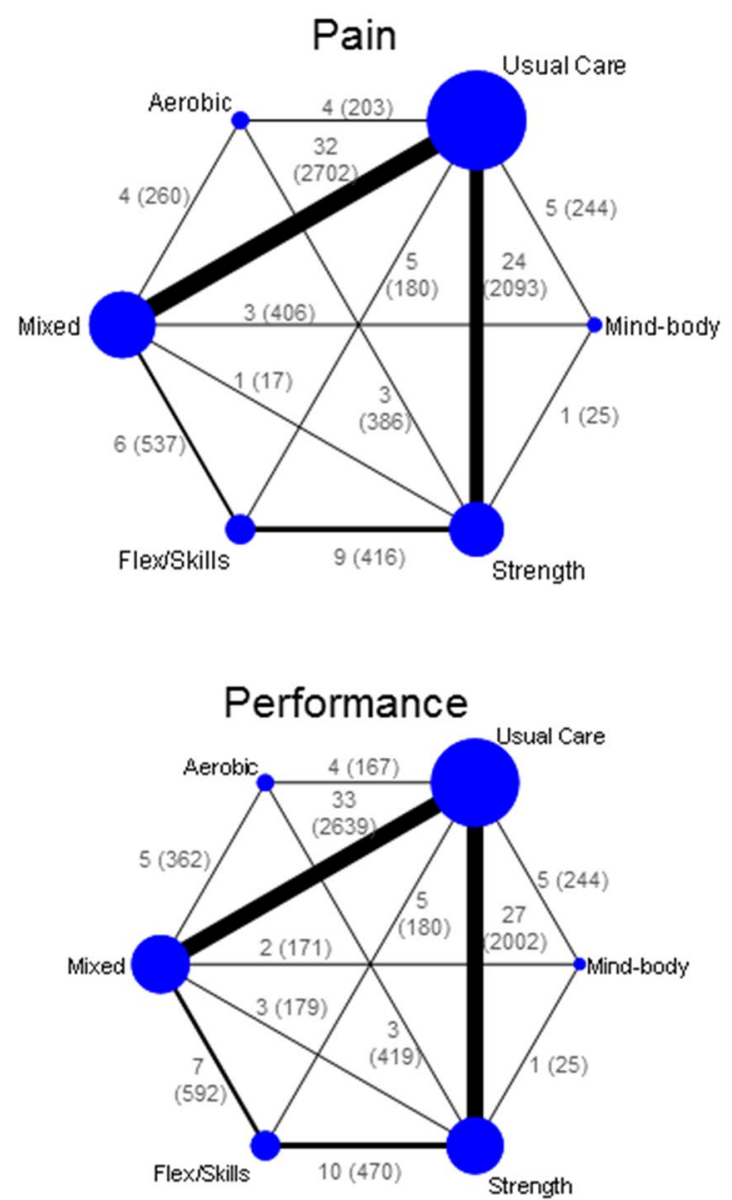

Fig. 2 Network of direct comparisons formed by included studies. The size of nodes and lines connecting the nodes are proportionate to the number of participants and the number of trials, respectively. Data
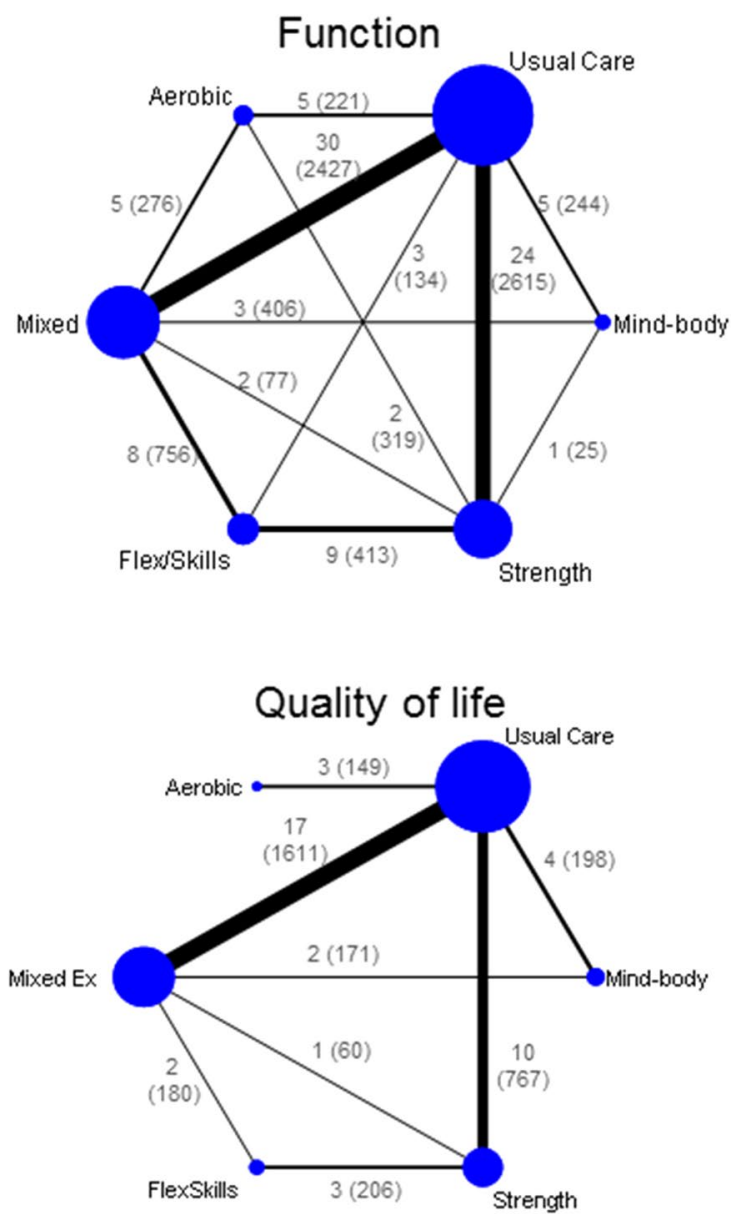

represent number of trials (number of participants). Flex/Skills flexibility and skills or neuromuscular training 
The efficacy of different exercises compared with usual care and each other is represented in Fig. 3. For pain, function and performance, all types of exercise were significantly better than usual care, the ES ranging from ES 0.4-1.1. The largest effect was observed for aerobic and mind-body exercise for pain and function. By contrast, the benefits of exercise on QoL were not as marked, with the magnitude of ES ranging from 0.2 to 0.4 . Strengthening and flexibility/skill exercises had a moderate ES, whereas mixed exercise gave the minimum ES for all outcomes and was significantly less effective than aerobic or mind-body exercise for pain. The median ranking largely corresponded to the magnitude of ES shown by each exercise. Aerobic was the best-ranked exercise for pain and performance, whereas mind-body was also the best-ranked for pain and self-reported function. Strengthening and flexibility/skill generally received mid-level rankings while mixed exercise was the lowest ranked exercise, superior only to usual care (ESM Appendix 4). Meta-regression demonstrated significant trend for pain $(p=0.01)$ but not for three other outcomes (function, $p=0.07$; performance, $p=0.06$; QoL, $p=0.65$ ), according to the effect sizes of outcome in descending order. Evidence of lack of model fit was found for pain $\left(\bar{D}_{\text {res }}: 189.3,185\right.$ data points; deviant studies were mainly small studies), performance ( $\bar{D}_{\text {res }}: 201.1,194$ arm-level data points; deviant study recruited younger than average patients-mean age 40 years), and QoL ( $\bar{D}_{\text {res }}: 86.3,81$ data points; possibly due to non-homogeneous groups). The model fit for function, on the other hand, was good ( $\bar{D}_{\text {res }}: 183.2,182$ data points). There was significant heterogeneity for all outcomes with the mean between-studies standard deviation ranging from 0.25 to 0.74 . No disagreements were found between direct and indirect evidence (ESM Appendix 5) or between estimates from different study designs.

Physician and participant blinding was not achieved in any study (ESM Appendix 6). The risk of bias assessment for individual items per article is detailed in ESM Appendix 7. Sample size, allocation concealment and SD imputation were used for assessing the robustness of the NMA estimate. As there were only seven studies with sample size $>100 /$ arm, we undertook a sensitivity analysis based on $\geq 30$ participants/arm - a consensus of the minimum sample size for a trial [131]. The analysis as summarised in ESM Appendix 8 suggested that the results obtained are robust.

Subgroup analysis by joint confirmed the exercise benefits in knee OA for pain, self-reported function and performance, whereas substantial uncertainty for benefits was observed in hip OA. In addition, exercise appeared to be more beneficial among participants who were not awaiting TJR compared with those who were (Table 3).

\section{Discussion}

This NMA confirms that exercise is beneficial for people with knee and hip OA for outcomes of pain, function, performance and QoL. In additon, we have found (1) aerobic and mind-body exercise have the largest ES for improvements in pain and function; (2) strengthening and flexibility/skill exercises improve multiple outcomes to a varying degree;

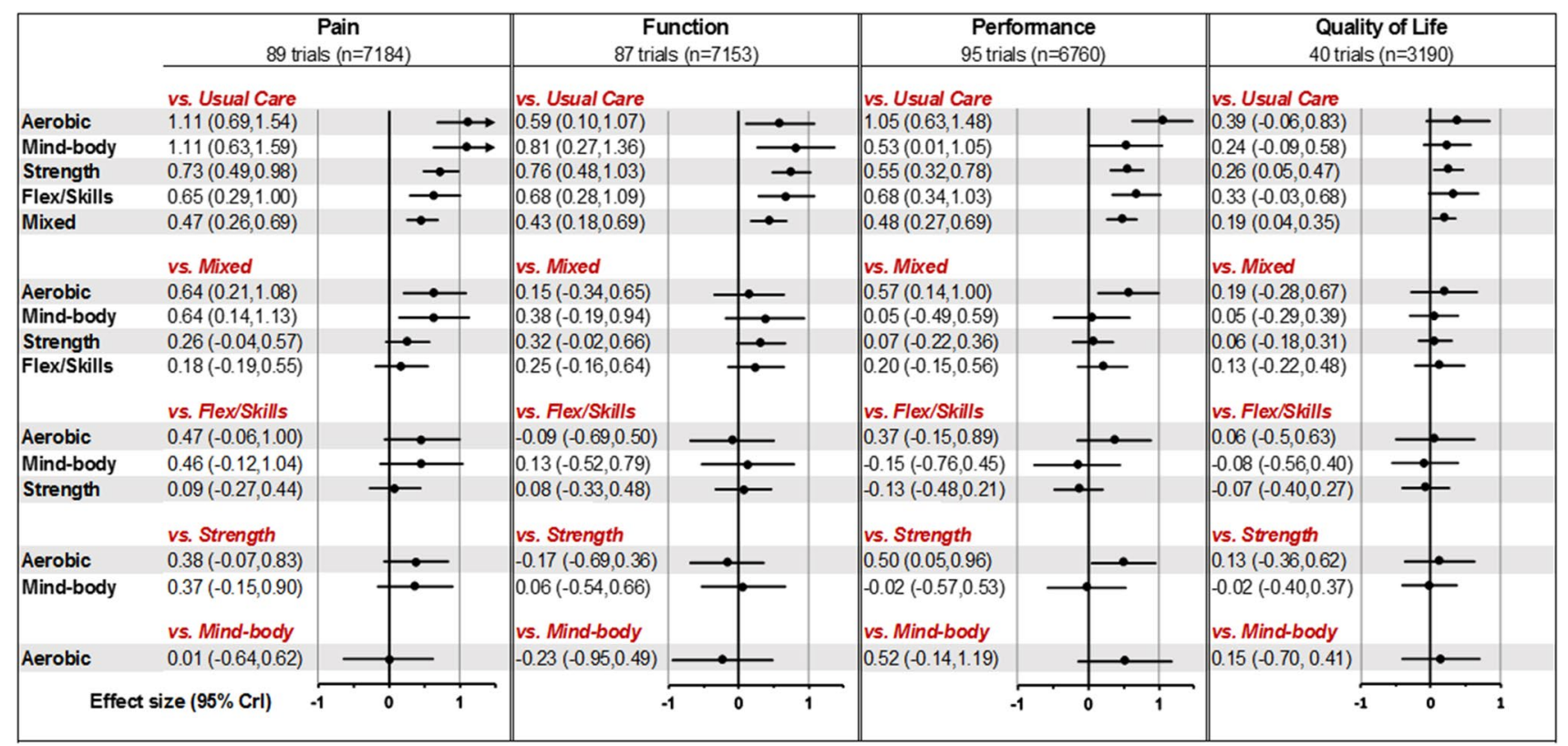

Fig. 3 Effect size of different exercise types versus different comparators presented in standardised means difference (95\% credibility interval). Flex/Skills flexibility and skills exercises, $n$ number analysed 
Table 3 Subgroup analysis by joint and recruitment

\begin{tabular}{|c|c|c|c|c|}
\hline & \multicolumn{4}{|c|}{ Effect size (95\% credibility interval) } \\
\hline & \multicolumn{2}{|l|}{ Joint } & \multicolumn{2}{|l|}{ Recruitment } \\
\hline & Knee OA & Hip OA & Not awaiting TJR & Awaiting TJR \\
\hline Pain & 75 trials $(n=5607)$ & 8 trials $(n=703)$ & 75 trials $(n=6393)$ & 14 trials $(n=791)$ \\
\hline Aerobic & $1.16(0.70,1.61)$ & & $1.15(0.73,1.59)$ & \\
\hline Mind-body & $1.30(0.73,1.86)$ & & $1.13(0.65,1.61)$ & \\
\hline Strength & $0.76(0.50,1.02)$ & $0.53(-0.74,1.80)$ & $0.81(0.54,1.08)$ & $0.46(-0.28,1.18)$ \\
\hline Flex/skills & $0.69(0.31,1.07)$ & & $0.70(0.33,1.07)$ & $0.58(-1.20,2.35)$ \\
\hline Mixed & $0.57(0.29,0.85)$ & $0.12(-0.36,0.62)$ & $0.52(0.29,0.76)$ & $0.25(-0.42,0.93)$ \\
\hline Heterogeneity & $0.67(0.54,0.82)$ & $0.54(0.22,1.20)$ & $0.62(0.51,0.77)$ & $0.81(0.47,1.37)$ \\
\hline Function & 73 trials $(n=5733)$ & 9 trials $(n=754)$ & 76 trials $(n=6564)$ & 11 trials $(n=589)$ \\
\hline Aerobic & $0.64(0.11,1.17)$ & & $0.63(0.19,1.07)$ & $0.12(-3.11,3.38)$ \\
\hline Mind-body & $0.93(0.27,1.59)$ & & $0.83(0.35,1.30)$ & \\
\hline Strength & $0.78(0.47,1.09)$ & $0.69(-0.17,1.54)$ & $0.72(0.46,0.99)$ & $0.90(-0.58,2.36)$ \\
\hline Flex/skills & $0.74(0.29,1.19)$ & & $0.68(0.33,1.03)$ & \\
\hline Mixed & $0.55(0.21,0.89)$ & $0.15(-0.17,0.46)$ & $0.46(0.23,0.69)$ & $0.09(-1.53,1.71)$ \\
\hline Heterogeneity & $0.81(0.67,0.98)$ & $0.32(0.05,0.75)$ & $0.61(0.50,0.74)$ & $1.69(1.00,2.97)$ \\
\hline Performance & 78 trials $(n=5208)$ & 10 trials $(n=905)$ & 81 trials $(n=6331)$ & 14 trials $(n=682)$ \\
\hline Aerobic & $1.12(0.61,1.62)$ & $0.81(0.23,1.42)$ & $1.05(0.62,1.49)$ & \\
\hline Mind-body & $0.68(0.03,1.31)$ & & $0.53(0.01,1.07)$ & \\
\hline Strength & $0.60(0.33,0.87)$ & $0.29(-0.13,0.75)$ & $0.51(0.25,0.77)$ & $0.78(0.13,1.43)$ \\
\hline Flex/skills & $0.76(0.38,1.14)$ & & $0.66(0.30,1.03)$ & $0.90(-0.72,2.53)$ \\
\hline Mixed & $0.60(0.31,0.90)$ & $0.17(-0.04,0.41)$ & $0.50(0.27,0.74)$ & $0.35(-0.26,0.97)$ \\
\hline Heterogeneity & $0.72(0.58,0.87)$ & $0.18(0.01,0.51)$ & $0.65(0.53,0.79)$ & $0.71(0.41,1.21)$ \\
\hline Quality of life & 30 trials $(n=2073)$ & 7 trials $(n=585)$ & 30 trials $(n=2620)$ & 10 trials $(n=570)$ \\
\hline Aerobic & $0.39(-0.13,0.93)$ & & $0.38(-0.02,0.79)$ & \\
\hline Mind-body & $0.37(-0.11,0.86)$ & & $0.25(-0.05,0.55)$ & \\
\hline Strength & $0.27(0.00,0.54)$ & $0.30(-0.37,0.97)$ & $0.36(0.12,0.62)$ & $0.13(-0.40,0.66)$ \\
\hline Flex/skills & $0.35(-0.10,0.80)$ & & $0.41(0.07,0.74)$ & \\
\hline Mixed & $0.25(-0.02,0.52)$ & $0.06(-0.21,0.36)$ & $0.22(0.07,0.38)$ & $0.10(-0.56,0.79)$ \\
\hline Heterogeneity & $0.35(0.19,0.54)$ & $0.19(0.00,0.70)$ & $0.19(0.03,0.36)$ & $0.53(0.19,1.09)$ \\
\hline
\end{tabular}

Heterogeneity presented as between-studies standard deviation and $95 \%$ credibility interval $(\mathrm{CrI})$

Flex/Skills flexibility/skills exercise, $n$ number of participants analysed, $O A$ osteoarthritis, TJR total joint replacement and (3) mixed exercise (more than one core type) is the least effective exercise across all outcomes and is significantly inferior to aerobic and mind-body exercise for pain.

The results of this NMA differ from the previous NMA by Uthman et al. [8] for the following possible methodological reasons. Firstly, this NMA was primarily designed to examine the relative efficacy between exercises in knee and hip OA, whereas Uthman et al. set out to examine the conclusiveness of the available evidence for exercise using trial sequential analysis. Secondly, our study included 103 trials, whereas the previous NMA included only 60 . Thirdly, we used a different exercise classification. Our classification was based on the ACSM criteria [11] but included an additional mind-body exercise and a 'mixed' exercise category (that grouped all exercise combinations together irrespective of whether it was two or more different types of exercise). The previous review, on the other hand, examined only three types of exercise (aerobic, flexibility and strengthening) either individually or in combinations of two, or all three. Their results showed that combinations of any two types of exercise tended to have smaller ESs and lower probability of being the best, whereas when all three were combined the overall ES was considerably larger. Fourthly, the previous review used non-exercise controls, which could include other interventions (e.g. patient education, electrotherapy), whereas we used usual care with no new interventions (e.g. 'waiting-list' or no intervention apart from usual care/activities). Estimation performed in this way is more precise as treatment effects vary with the type of controls, even with inert agents [132]. Finally, we examined four outcomes (pain, self-reported function, observed performance and QoL), whereas the previous review examined only two 
(pain and function). Both reviews agree that the effect of exercise depends on the types of exercise or components of the exercise programme. Our results align with other conventional systematic reviews and meta-analyses where aerobic [133] and mind-body exercise [134] tend to have larger effect sizes than strengthening exercise, and mixed exercise tends to have the lowest effect size for pain [5]. Also in line with the literature is the smaller effect size and greater uncertainties of exercise benefits in hip compared with knee $\mathrm{OA}[4,135]$, which still requires further investigation.

A novel finding from this NMA is that we were able to demonstrate that mind-body exercise had similar effects to aerobic exercise for pain. Mind-body exercise such as tai chi and yoga can be characterised as low to moderate intensity exercise performed with an intentional awareness (mindfulness) on breathing and slow controlled movement [136]. Although the underlying mechanism remains unclear, the effect of both aerobic and mind-body exercise may be attributable to the potential of these exercises to influence altered central elements such as central pain sensitisation, sleep disturbance, and mood disorders [137, 138]. Pain experience as well as level of function and QoL are the results of interactions between these central impairments and peripheral pain mechanisms [139, 140]. As aerobic and mind-body exercise could influence both central and peripheral pain mechanisms, this additive effect may explain their additional benefits over other exercises that predominantly address only joint level deficits.

There is no satisfactory biological explanation for the poor efficacy of mixed exercise across all outcomes, particularly when considering that there are many domains of physical impairment in people with OA. However, it may be that the lack of response to mixed exercise reflects flawed implementation of the programme, such that intensity of the individual components was insufficient or poorly adhered to due to the complexity of the regimen compared with a single exercise programme.

There are limitations to this NMA. A key limitation is that we were fully reliant on author descriptions for the classification of exercises and control groups. Exercise programmes and 'usual care' are not standardised and vary considerably between studies. Even when the focus of exercise is strength improvement, it is typical to also find some elements of flexibility and/or aerobic exercise included in the programme. As far as possible, we adhered to the classification presented by the authors. The decision to group different types of controls, such as waiting list, usual physical activity and usual care, together for the analysis is open to question. Unlike non-pharmacological treatments for mental health, where a difference between non-treatment and waiting-list controls has been observed [141], no such distinction has been reported for exercise interventions in OA. Instead, many published reports in OA extend controls to include other types of non-exercise interventions (e.g. patient education and behavioural therapy) rather than limiting them to 'usual care' $[4,142]$. Secondly, the estimates for aerobic, mind-body and flexibility/skill exercises were open to considerable uncertainty with wide credibility intervals as the number of studies were small. However, examination of exercise rankings using different approaches (i.e. probability of the exercise being the best, highest median ranking, or magnitude of ES) showed that the estimates were generally in agreement, supporting the trend observed. Another caveat is that we did not fully explore the reasons for heterogeneity because efforts to identify covariates for exercise effect in OA have generally been unsuccessful in many meta-analyses $[8,143]$. This probably requires more sophisticated analytical approaches and warrants separate reporting. Finally, the focus of the included studies was relatively short term and involved mainly single-joint OA. Therefore, we could not determine whether the observed differences between exercises would persist in the longer term or whether people with knee plus hip OA would attain similar exercise benefits.

\section{Conclusions}

In conclusion, this NMA confirms that exercise therapy has clear benefits for people with knee and hip OA and also shows that the magnitude of effect varies according to type of exercise and outcome of interest. Aerobic and mind-body exercises were found to be the best for pain and function, whereas strengthening and flexibility/skill exercises are potentially next best for multiple outcomes. Mixed exercise is the least effective exercise for knee and hip OA but is still superior to usual care for all outcomes and therefore remains an acceptable option for patients who do not respond well to single-component exercises. The findings of this review may help clinicians guide their prescription of exercise type with respect to treatment outcomes. Further research is warranted to confirm if the hierarchy observed are consistent across all patients with OA.

Acknowledgements We are grateful to Wei Jie from Central South University, China for sharing her expertise during the preliminary analysis and Prof. Mark Batt from University of Nottingham for his constructive feedback rendered during the early phase of the work.

Data availability statement The datasets generated during and/or analysed during the current study are available from the corresponding author on reasonable request.

Author contributions SLG led the review, performed search and selection of articles, data extraction, analysis and interpretation as well as drafted the manuscript. MSMP, JS and YF performed validation of data. NJW developed WinBUGS code and advised on the Bayesian analysis of the data and interpretation. JHL, MH, MD and WZ validated study selection. All authors interpreted the results, edited and 
approved the manuscript. WZ conceptualised the project and is the guarantor of the study.

\section{Compliance with Ethical Standards}

Conflict of interest Nicky Welton declares that she received payment from the Association of British Pharmaceutical Industry to deliver a masterclass on Evidence Synthesis in submission to NICE. Weiya Zhang received honorarium from AstraZeneca and Grunthal for advice on treating chronic hyperuricaemia in people with gout, speaker fees/ reimbursements from Bioiberica for EULAR 2016 Satellite Symposium, OARSI for OARSI 2017, Korea College of Rheumatology annual congress 2018, EULAR for EULAR 2018, Heilongjiang Rheumatology Society for the annual meeting in 2018. Siew-Li Goh, Monica S.M. Persson, Joanne Stocks, Yunfei Hou, Jianhao Lin, Michelle C. Hall and Michael Doherty have no conflict of interest to declare.

Funding Arthritis Research UK for two centres of excellence Grants (Pain Centre and Sport, Exercise and Osteoarthritis Centre) (20777, 21595), and the Ministry of Education Malaysia and University of Malaya for a Ph.D. studentship (SL Goh).

Role of funding source The funders of the study had no role in study design, data collection, data analysis, data interpretation, or writing of the report.

Open Access This article is distributed under the terms of the Creative Commons Attribution 4.0 International License (http://creativeco mmons.org/licenses/by/4.0/), which permits unrestricted use, distribution, and reproduction in any medium, provided you give appropriate credit to the original author(s) and the source, provide a link to the Creative Commons license, and indicate if changes were made.

\section{References}

1. Vos T, Flaxman AD, Naghavi M, et al. Years lived with disability (YLDs) for 1160 sequelae of 289 diseases and injuries 1990-2010: a systematic analysis for the Global Burden of Disease Study 2010. Lancet. 2012;380(9859):2163-96.

2. Nelson AE, Allen KD, Golightly YM, Goode AP, Jordan JM. A systematic review of recommendations and guidelines for the management of osteoarthritis: the chronic osteoarthritis management initiative of the U.S. bone and joint initiative. Semin Arthritis Rheum. 2014;43(6):701-12.

3. Bartels EM, Juhl CB, Christensen R, et al. Aquatic exercise for the treatment of knee and hip osteoarthritis. Cochrane Database Syst Rev. 2016;3:CD005523.

4. Fransen M, McConnell S. Exercise for osteoarthritis of the knee. Cochrane Database Syst Rev. 2015;1.

5. Juhl C, Christensen R, Roos EM, Zhang W, Lund H. Impact of exercise type and dose on pain and disability in knee osteoarthritis. Arthritis Rheumatol. 2014;66(3):622-36.

6. Cipriani A, Higgins JPT, Geddes JR, Salanti G. Conceptual and technical challenges in network meta-analysis. Ann Intern Med. 2013;159(2):130-7.

7. Caldwell DM. An overview of conducting systematic reviews with network meta-analysis. Syst Rev. 2014;3(1):1-4.

8. Uthman OA, van der Windt DA, Jordan JL, et al. Exercise for lower limb osteoarthritis: systematic review incorporating trial sequential analysis and network meta-analysis. Br J Sports Med. 2014;48(21):1579.
9. Goh S-L, Persson MS, Bhattacharya A, Hall M, Doherty M, Zhang W. Relative efficacy of different types of exercise for treatment of knee and hip osteoarthritis: protocol for network metaanalysis of randomised controlled trials. Syst Rev. 2016;5(1):147.

10. Deschenes M, Garber CE. General principles of exercise prescription. In: Pescatello LS, Arena R, Riebe D, Thompson PD, editors. ACSM's guidelines for exercise testing and prescription. 9th ed. Baltimore: Lippincott Williams \& Wilkins; 2013. p. 162-93.

11. Regnaux JP, Lefevre-Colau MM, Trinquart L, et al. High-intensity versus low-intensity physical activity or exercise in people with hip or knee osteoarthritis. Cochrane Database Syst Rev. 2015;10.

12. Fu R, Vandermeer BW, Shamliyan TA, O'Neil ME, Yazdi F, Fox $\mathrm{SH}$, Morton SC. Handling continuous outcomes in quantitative synthesis. In: Methods guide for effectiveness and comparative effectiveness reviews [Internet]. Agency for Healthcare Research and Quality (US); 2013.

13. Dias S, Ades AE, Welton NJ, Sutton AJ. Network meta-analysis for decision-making. Hoboken: John Wiley \& Sons Ltd; 2018.

14. Mbuagbaw L, Rochwerg B, Jaeschke R, et al. Approaches to interpreting and choosing the best treatments in network metaanalyses. Syst Rev. 2017;6(1):79.

15. Renehan AG, Tyson M, Egger M, Heller RF, Zwahlen M. Bodymass index and incidence of cancer: a systematic review and meta-analysis of prospective observational studies. Lancet. 2008;371(9612):569-78.

16. Dias S, Welton N, Caldwell D, Ades A. Checking consistency in mixed treatment comparison meta-analysis. Stat Med. 2010;29(7-8):932-44.

17. Higgins JPT, Jackson D, Barrett JK, Lu G, Ades AE, White IR. Consistency and inconsistency in network meta-analysis: concepts and models for multi-arm studies. Res Synth Methods. 2012;3(2):98-110.

18. Abbott JH, Robertson MC, Chapple C, et al. Manual therapy, exercise therapy, or both, in addition to usual care, for osteoarthritis of the hip or knee: a randomized controlled trial. 1: clinical effectiveness. Osteoarthr Cartil. 2013;21(4):525-34.

19. Aglamis B, Toraman NF, Yaman H. The effect of a 12-week supervised multicomponent exercise program on knee OA in Turkish women. J Back Musculoskelet Rehabil. 2008;21(2):121-8.

20. Ağlamış B, Toraman NF, Yaman H. Change of quality of life due to exercise training in knee osteoarthritis: SF-36 and Womac. J Back Musculoskelet Rehabil. 2009;22(1):43-8.

21. An B, Dai K, Zhu Z, Wang Y, Hao Y, Tang T, Yan H. Baduanjin alleviates the symptoms of knee osteoarthritis. J Altern Complement Med. 2008;14(2):167-74.

22. Aoki O, Tsumura N, Kimura A, Okuyama S, Takikawa S, Hirata $\mathrm{S}$. Home stretching exercise is effective for improving knee range of motion and gait in patients with knee osteoarthritis. J Phys Ther Sci. 2009;21(2):113-9.

23. Arnold CM, Faulkner RA. The effect of aquatic exercise and education on lowering fall risk in older adults with hip osteoarthritis [corrected] [published erratum appears in J AGING PHYS ACTIVITY 2010 Oct;18(4):477-479]. J Aging Phys Act. 2010;18(3):245-60.

24. Beaupre LA, Lier D, Davies DM, Johnston DB. The effect of a preoperative exercise and education program on functional recovery, health related quality of life, and health service utilization following primary total knee arthroplasty. J Rheumatol. 2004;31(6): 1166-73.

25. Bennell KL, Hunt MA, Wrigley TV, et al. Hip strengthening reduces symptoms but not knee load in people with medial knee osteoarthritis and varus malalignment: a randomised controlled trial. Osteoarthr Cartil. 2010;18(5):621-8. 
26. Bennell KL, Kyriakides M, Metcalf B, et al. Neuromuscular versus quadriceps strengthening exercise in patients with medial knee osteoarthritis and varus malalignment: a randomized controlled trial. Arthritis Rheumatol. 2014;66(4):950-9.

27. Bieler T, Siersma V, Magnusson S, Kjaer M, Christensen H, Beyer N. In hip osteoarthritis, Nordic walking is superior to strength training and home-based exercise for improving function. Scand J Med Sci Sports. 2017;27(8):873-86.

28. Börjesson M, Robertson E, Weidenhielm L, Mattsson E, Olsson E. Physiotherapy in knee osteoarthrosis: effect on pain and walking. Physiother Res Int. 1996;1(2):89-97.

29. Braghin RMB, Libardi EC, Junqueira C, Nogueira-Barbosa $\mathrm{MH}$, de Abreu DCC. Exercise on balance and function for knee osteoarthritis: a randomized controlled trial. J Bodyw Mov Ther. 2018;22(1):76-82.

30. Bruce-Brand RA, Walls RJ, Ong JC, Emerson BS, O'Byrne JM, Moyna NM. Effects of home-based resistance training and neuromuscular electrical stimulation in knee osteoarthritis: a randomized controlled trial. BMC Musculoskelet Disord. 2012;13:118 Epub 2012.

31. Calatayud J, Casaña J, Ezzatvar Y, Jakobsen MD, Sundstrup E, Andersen LL. High-intensity preoperative training improves physical and functional recovery in the early post-operative periods after total knee arthroplasty: a randomized controlled trial. Knee Surg Sports Traumatol Arthrosc. 2017;25(9):2864-72.

32. Chaipinyo K, Karoonsupcharoen O. No difference between home-based strength training and home-based balance training on pain in patients with knee osteoarthritis: a randomised trial. Aust J Physiother. 2009;55(1):25-30.

33. Chen TW, Lin CW, Lee CL, et al. The efficacy of shock wave therapy in patients with knee osteoarthritis and popliteal cyamella. Kaohsiung J Med Sci. 2014;30(7):362-70.

34. Cheung C, Wyman JF, Bronas U, McCarthy T, Rudser K, Mathiason MA. Managing knee osteoarthritis with yoga or aerobic/ strengthening exercise programs in older adults: a pilot randomized controlled trial. Rheumatol Int. 2017;37(3):389-98.

35. Chopp-Hurley JN, Brenneman EC, Wiebenga EG, Bulbrook B, Keir PJ, Maly MR. Randomized controlled trial investigating the role of exercise in the workplace to improve work ability, performance, and patient-reported symptoms among older workers with osteoarthritis. J Occup Environ Med. 2017;59(6):550-6.

36. Christensen R, Henriksen M, Leeds AR, et al. Effect of weight maintenance on symptoms of knee osteoarthritis in obese patients: a twelve-month randomized controlled trial [with consumer summary]. Arthritis Care Res. 2015;67(5):640-50.

37. Henriksen M, Christensen R, Hunter DJ, et al. Structural changes in the knee during weight loss maintenance after a significant weight loss in obese patients with osteoarthritis: a report of secondary outcome analyses from a randomized controlled trial. Osteoarthr Cartil. 2014;22(5):639-46.

38. Cochrane T, Davey RC, Matthes Edwards SM. Randomised controlled trial of the cost-effectiveness of water-based therapy for lower limb osteoarthritis. Health Technol Assess (Winchester, England). 2005;9(31):1-130.

39. Cheung C, Wyman JF, Resnick B, Savik K. Yoga for managing knee osteoarthritis in older women: a pilot randomized controlled trial. BMC Complement Altern Med. 2014;14:160.

40. D'Lima DD, Colwell CW Jr, Morris BA, Hardwick ME, Kozin F. The effect of preoperative exercise on total knee replacement outcomes. Clin Orthop Relat Res. 1996;326:174-82.

41. Duracoglu D, Aydin R, Baskent A, Celik A. Effects of kinesthesia and balance exercises in knee osteoarthritis. J Clin Rheumatol. 2005;11(6):303-10.

42. Ebnezar J, Nagarathna R, Yogitha B, Nagendra HR. Effect of integrated yoga therapy on pain, morning stiffness and anxiety in osteoarthritis of the knee joint: a randomized control study. Int J Yoga. 2012;5(1):28-36.

43. Ebnezar J, Yogitha B. Effectiveness of yoga therapy with the therapeutic exercises on walking pain, tenderness, early morning stiffness and disability in osteoarthritis of the knee joint-a comparative study. J Yoga Phys Ther. 2012;2(3):114.

44. Ebnezar J, Nagarathna R, Yogitha B, Nagendra HR. Effects of an integrated approach of hatha yoga therapy on functional disability, pain, and flexibility in osteoarthritis of the knee joint: a randomized controlled study. J Altern Complement Med. 2012;18(5):463-72.

45. Ebnezar J, Nagarathna R, Bali Y, Nagendra HR. Effect of an integrated approach of yoga therapy on quality of life in osteoarthritis of the knee joint: a randomized control study. Int J Yoga. 2011;4(2):55-63.

46. Espejo Antunez L, Cardero Duran MA, Caro Puertolas B, Tellez de Peralta G. Efectos del ejercicio fisico en la funcionalidad y calidad de vida en mayores institucionalizados diagnosticados de gonartrosis (Effects of exercise on the function and quality of life in the institutionalised elderly diagnosed with gonarthrosis) [Spanish]. Rev Esp Geriatr Gerontol. 2012;47(6):262-5.

47. Ettinger WH, Burns R, Messier SP, et al. A randomized trial comparing aerobic exercise and resistance exercise with a health education program in older adults with knee osteoarthritis: the fitness arthritis and seniors trial (FAST). JAMA. 1997;277(1):25-31.

48. Evcik D, Sonel B. Effectiveness of a home-based exercise therapy and walking program on osteoarthritis of the knee. Rheumatol Int. 2002;22(3):103-6.

49. Evgeniadis G, Beneka A, Malliou P, Mavromoustakos S, Godolias G. Effects of pre- or postoperative therapeutic exercise on the quality of life, before and after total knee arthroplasty for osteoarthritis. J Back Musculoskelet Rehabil. 2008;21(3):161-9.

50. Ferrara PE, Rabini A, Maggi L, et al. Effect of pre-operative physiotherapy in patients with end-stage osteoarthritis undergoing hip arthroplasty.[Erratum appears in Clin Rehabil. 2008 Dec;22(12):1137 Note: Lombi, G Magliocchetti [corrected to Magliocchetti, G]]. Clin Rehabil. 2008;22(10-11):977-86.

51. Fitzgerald GK, Piva SR, Gil AB, Wisniewski SR, Oddis CV, Irrgang JJ. Agility and perturbation training techniques in exercise therapy for reducing pain and improving function in people with knee osteoarthritis: a randomized clinical trial. Phys Ther. 2011;91(4):452-69.

52. Fransen M, Crosbie J, Edmonds JO. Physical therapy is effective for patients with osteoarthritis of the knee: a randomized controlled clinical trial. J Rheumatol. 2001;28(1):156-64.

53. Fransen M, Nairn L, Winstanley J, Lam P, Edmonds J. Physical activity for osteoarthritis management: a randomized controlled clinical trial evaluating hydrotherapy or Tai Chi classes. Arthritis Rheum Arthritis Care Res. 2007;57(3):407-14.

54. French HP, Cusack T, Brennan A, et al. Exercise and manual physiotherapy arthritis research trial (EMPART) for osteoarthritis of the hip: a multicenter randomized controlled trial. [Erratum appears in Arch Phys Med Rehabil. 2013 Mar;94(3):600 Note: Fitzpatrick, Martina [added]]. Arch Phys Med Rehabil. 2013;94(2):302-14.

55. Ghroubi S, Elleuch H, Kaffel N, Echikh T, Abid M, Elleuch $\mathrm{MH}$. Contribution of exercise and diet in the management of knee osteoarthritis in the obese. Ann Readapt Med Phys. 2008;51(8):663-70.

56. Gomiero AB, Kayo A, Abraão M, Peccin MS, Grande AJ, Trevisani VF. Sensory-motor training versus resistance training among patients with knee osteoarthritis: randomized single-blind controlled trial. Sao Paulo Med J. 2018;136(1):44-50.

57. Gondhalekar GA, Deo MV. Retrowalking as an adjunct to conventional treatment versus conventional treatment alone on pain 
and disability in patients with acute exacerbation of chronic knee osteoarthritis: a randomized clinical trial. N Am J Med Sci. 2013;5(2):108-12.

58. Gur H, Cakin N, Akova B, Okay E, Kucukoglu S. Concentric versus combined concentric-eccentric isokinetic training: effects on functional capacity and symptoms in patients with osteoarthrosis of the knee. Arch Phys Med Rehabil. 2002;83(3):308-16.

59. Hasegawa R, Islam MM, Nasu E, et al. Effects of combined balance and resistance exercise on reducing knee pain in community-dwelling older adults. Phys Occup Ther Geriatr. 2010;28(1):44-56.

60. Henriksen M, Klokker L, Graven-Nielsen T, et al. Association of exercise therapy and reduction of pain sensitivity in patients with knee osteoarthritis: a randomized controlled trial. Arthritis Care Res. 2014;66(12):1836-43.

61. Henriksen M, Klokker L, Bartholdy C, Schjoedt-Jorgensen T, Bandak E, Bliddal $\mathrm{H}$. No effects of functional exercise therapy on walking biomechanics in patients with knee osteoarthritis: exploratory outcome analyses from a randomised trial. BMJ Open Sport Exerc Med. 2017;2(1):bmjsem-2017-000230.

62. Hermann A, Holsgaard-Larsen A, Zerahn B, Mejdahl S, Overgaard S. Preoperative progressive explosive-type resistance training is feasible and effective in patients with hip osteoarthritis scheduled for total hip arthroplasty-a randomized controlled trial. Osteoarthr Cartil. 2016;24(1):91-8.

63. Hinman RS, Heywood SE, Day AR. Aquatic physical therapy for hip and knee osteoarthritis: results of a single-blind randomized controlled trial. Phys Ther. 2007;87(1):32-43.

64. Hiyama Y, Yamada M, Kitagawa A, Tei N, Okada S. A four-week walking exercise programme in patients with knee osteoarthritis improves the ability of dual-task performance: a randomized controlled trial. Clin Rehabil. 2012;26(5):403-12.

65. Hoogeboom TJ, Dronkers JJ, van den Ende CHM, Oosting E, van Meeteren NLU. Preoperative therapeutic exercise in frail elderly scheduled for total hip replacement: a randomized pilot trial [with consumer summary]. Clin Rehabil. 2010;24(10):901-10.

66. Huang MH, Lin YS, Yang RC, Lee CL. A comparison of various therapeutic exercises on the functional status of patients with knee osteoarthritis. Semin Arthritis Rheum. 2003;32(6):398-406.

67. Huang MH, Yang RC, Lee CL, Chen TW, Wang MC. Preliminary results of integrated therapy for patients with knee osteoarthritis. Arthritis Care Res. 2005;53(6):812-20.

68. Huang L, Guo B, Xu F, Zhao J. Effects of quadriceps functional exercise with isometric contraction in the treatment of knee osteoarthritis. Int J Rheum Dis. 2018;21(5):952-59.

69. Hunt MA, Pollock CL, Kraus VB, et al. Relationships amongst osteoarthritis biomarkers, dynamic knee joint load, and exercise: results from a randomized controlled pilot study. BMC Musculoskelet Disord. 2013;14:115 Epub 2013.

70. Ikuta F, Deguchi H, Okamoto K, et al. Effects of knee internal rotation exercises on knee adduction moment and function of elderly women with knee osteoarthritis: a randomized controlled trial. Rigakuryoho Kagaku. 2015;30(3):339-44.

71. Jan M-H, Lin J-J, Liau J-J, Lin Y-F, Lin D-H. Investigation of clinical effects of high- and low-resistance training for patients with knee osteoarthritis: a randomized controlled trial. Phys Ther. 2008;88(4):427-36.

72. Jan M-H, Lin C-H, Lin Y-F, Lill J-J, Lin D-H. Effects of weightbearing versus nonweight-bearing exercise on function, walking speed, and position sense in participants with knee osteoarthritis: a randomized controlled trial. Arch Phys Med Rehabil. 2009;90(6):897-904.

73. Jorge RTB, Souza MC, Chiari A, et al. Progressive resistance exercise in women with osteoarthritis of the knee: a randomized controlled trial. Clin Rehabil. 2015;29(3):234-43.
74. Juhakoski R, Tenhonen S, Malmivaara A, Kiviniemi V, Anttonen T, Arokoski JP. A pragmatic randomized controlled study of the effectiveness and cost consequences of exercise therapy in hip osteoarthritis [with consumer summary]. Clin Rehabil. 2011;25(4):370-83.

75. Krasilshchikov O, Sungkit NB, Shihabudin TM, Shaw I, Shaw BS. Effects of an eight-week training programme on pain relief and physical condition of overweight and obese women with early stage primary knee osteoarthritis. Afr J Phys Health Educ Recreat Dance. 2011;17(2):328-39.

76. Krauß I, Steinhilber B, Haupt G, Miller R, Martus P, Janßen P. Exercise therapy in hip osteoarthritis-a randomized controlled trial. Dtsch Arztebl Int. 2014;111(35-36):592-9.

77. Steinhilber B, Haupt G, Miller R, Janssen P, Krauss I. Exercise therapy in patients with hip osteoarthritis: effect on hip muscle strength and safety aspects of exercise-results of a randomized controlled trial. Mod Rheumatol. 2017;27(3):493-502.

78. Kreindler H, Lewis CB, Rush S, Schaefer K. Effects of three exercise protocols on strength of persons with osteoarthritis of the knee. Top Geriatr Rehabil. 1989;4(3):32-9.

79. Kumar S, Kumar A, Kumar R. Proprioceptive training as an adjunct in osteoarthritis of knee. J Musculoskelet Res. 2013;16(1):1350002.

80. Lee HY, Lee KJ. Effects of Tai Chi exercise in elderly with knee osteoarthritis. Daehan Ganho Haghoeji. 2008;38(1):11-8.

81. Lee H-J, Park H-J, Chae Y, et al. Tai Chi Qigong for the quality of life of patients with knee osteoarthritis: a pilot, randomized, waiting list controlled trial. Clin Rehabil. 2009;23(6):504-11.

82. Lim B-W, Hinman RS, Wrigley TV, Sharma L, Bennell KL. Does knee malalignment mediate the effects of quadriceps strengthening on knee adduction moment, pain, and function in medial knee osteoarthritis? A randomized controlled trial. Arthritis Rheum Arthritis Care Res. 2008;59(7):943-51.

83. Lin D-H, Lin Y-F, Chai H-M, Han Y-C, Jan M-H. Comparison of proprioceptive functions between computerized proprioception facilitation exercise and closed kinetic chain exercise in patients with knee osteoarthritis. Clin Rheumatol. 2007;26(4):520-8.

84. Lin D-H, Lin C-HJ, Lin Y-F, Jan M-H. Efficacy of 2 non-weightbearing interventions, proprioception training versus strength training, for patients with knee osteoarthritis: a randomized clinical trial. J Orthop Sports Phys Ther. 2009;39(6):450-7.

85. Lund $\mathrm{H}$, Weile $\mathrm{U}$, Christensen $\mathrm{R}$, et al. A randomized controlled trial of aquatic and land-based exercise in patients with knee osteoarthritis. J Rehabil Med (Stiftelsen Rehabiliteringsinformation). 2008;40(2):137-44.

86. Messier S, Thompson C, Ettinger W. Effects of long-term aerobic or weight training regimes on gait in an older, osteoarthritic population. J Appl Biomech. 1997;13(2):205-25.

87. Moghadam EB, Shojaedin SS. The effect of eight weeks aerobic training on functional indicators and range of motion in active older men with knee osteoarthritis. Razi J Med Sci. 2017;24(156):100-10.

88. Munukka M, Waller B, Rantalainen T, et al. Efficacy of progressive aquatic resistance training for tibiofemoral cartilage in postmenopausal women with mild knee osteoarthritis: a randomised controlled trial. Osteoarthr Cartil. 2016;24(10):1708-17.

89. Waller B, Munukka M, Rantalainen T, et al. Effects of high intensity resistance aquatic training on body composition and walking speed in women with mild knee osteoarthritis: a 4-month RCT with 12-month follow-up. Osteoarthr Cartil. 2017;25(8):1238-46.

90. Oida Y, Morozumi K, Nakamura N, et al. (Effectiveness of a community health service program using exercise intervention for elderly people with osteoarthritis of the knees: a randomized controlled trial) [Japanese]. Nippon Koshu Eisei Zasshi [Japanese Journal of Public Health]. 2008;55(4):228-37. 
91. Oosting E, Jans MP, Dronkers JJ, et al. Preoperative home-based physical therapy versus usual care to improve functional health of frail older adults scheduled for elective total hip arthroplasty: a pilot randomized controlled trial. Arch Phys Med Rehabil. 2012;93(4):610-6.

92. O'Reilly SC, Muir KR, Doherty M. Effectiveness of home exercise on pain and disability from osteoarthritis of the knee: a randomised controlled trial. Ann Rheum Dis. 1999;58(1):15-9.

93. Petrella RJ, Bartha C. Home based exercise therapy for older patients with knee osteoarthritis: a randomized clinical trial [with consumer summary]. J Rheumatol. 2000;27(9):2215-21.

94. Rapp W, Boeer J, Albrich C, Heitkamp HC. Efficiency of Vibration or Strength Training for Knee Stability in Osteoarthritis of the Knee. [German] Auswirkung eines Vibrations- und Krafttrainings auf die Beinmuskulatur bei Gonarthrosepatienten. Aktuelle Rheumatologie. 2009;34(4):240-5.

95. Rathi M, Palekar T, Varghese A. Efficacy of backward walking on patients with osteoarthritis of knee on quadriceps strength, pain and physical functions. Indian J Physiother Occup Ther. 2014;8(4):192-6.

96. Rogers MW, Tamulevicius N, Coetsee MF, Curry BF, Semple SJ. Knee osteoarthritis and the efficacy of kinesthesia, balance and agility exercise training: a pilot study. Int J Exerc Sci. 2011;4(2):122-32.

97. Rogers MW, Tamulevicius N, Semple SJ, Krkeljas Z. Efficacy of home-based kinesthesia, balance and agility exercise training among persons with symptomatic knee osteoarthritis [with consumer summary]. J Sports Sci Med. 2012;11(4):751-8.

98. Rogind H, Bibow-Nielsen B, Jensen B, Moller HC, FrimodtMoller $\mathrm{H}$, Bliddal $\mathrm{H}$. The effects of a physical training program on patients with osteoarthritis of the knees. Arch Phys Med Rehabil. 1998;79(11):1421-7.

99. de Rooij M, van der Leeden M, Cheung J, et al. Efficacy of tailored exercise therapy on physical functioning in patients with knee osteoarthritis and comorbidity: a randomized controlled trial [with consumer summary]. Arthritis Care Res. 2017;69(6):807-16.

100. Rosedale R, Rastogi R, May S, et al. Efficacy of exercise intervention as determined by the McKenzie system of mechanical diagnosis and therapy for knee osteoarthritis: a randomized controlled trial [with consumer summary]. J Orthop Sports Phys Ther. 2014;44(3):173-81.

101. Salacinski AJ, Krohn K, Lewis SF, Holland ML, Ireland K, Marchetti G. The effects of group cycling on gait and pain-related disability in individuals with mild-to-moderate knee osteoarthritis: a randomized controlled trial. J Orthop Sports Phys Ther. 2012;42(12):985-95.

102. Salli A, Sahin N, Baskent A, Ugurlu H. The effect of two exercise programs on various functional outcome measures in patients with osteoarthritis of the knee: a randomized controlled clinical trial. Isokinet Exerc Sci. 2010;18(4):201-9.

103. Salli A, Ugurlu H, Emlik D. Comparison of the effectiveness of concentric, combined concentric-eccentric and isometric exercises on symptoms and functional capacity in patients with knee osteoarthritis. Turkiye Fiziksel Tip ve Rehabilitasyon Dergisi. 2006;52(2):61-7.

104. Samut G, Dincer F, Ozdemir O. The effect of isokinetic and aerobic exercises on serum interleukin- 6 and tumor necrosis factor alpha levels, pain, and functional activity in patients with knee osteoarthritis. Mod Rheumatol. 2015;25(6):919-24.

105. Sayers SP, Gibson K, Cook CR. Effect of high-speed power training on muscle performance, function, and pain in older adults with knee osteoarthritis: a pilot investigation [with consumer summary]. Arthritis Care Res. 2012;64(1):46-55.
106. Schilke JM, Johnson GO, Housh TJ, Odell JR. Effects of muscle strength training on the functional status of patients with osteoarthritis of the knee joint. Nurs Res. 1996;45(2):68-72.

107. Sekir U, Gur H. A multi-station proprioceptive exercise program in patients with bilateral knee osteoarthrosis: functional capacity, pain and sensoriomotor function. A randomized controlled trial [with consumer summary]. J Sports Sci Med. 2005;4(4):590-603.

108. Simao AP, Avelar NC, Tossige-Gomes R, et al. Functional performance and inflammatory cytokines after squat exercises and whole-body vibration in elderly individuals with knee osteoarthritis. Arch Phys Med Rehabil. 2012;93(10):1692-700.

109. Singh J, Singh P, Sohal MS. Effect of exercise rehabilitation programme on clinical health status of osteoarthritis knee patients. Indian J Physiother Occup Ther. 2011;5(3):191-8.

110. Skoffer B, Maribo T, Mechlenburg I, Hansen PM, Søballe K, Dalgas U. Efficacy of preoperative progressive resistance training on postoperative outcomes in patients undergoing total knee arthroplasty. Arthritis Care Res. 2016;68(9):1239-51.

111. Sung-Bum JU, Gi Duck P, Sang-Soo KIM. Effects of proprioceptive circuit exercise on knee joint pain and muscle function in patients with knee osteoarthritis. J Phys Ther Sci. 2015;27(8):2439-41.

112. Swank AM, Kachelman JB, Bibeau W, et al. Prehabilitation before total knee arthroplasty increases strength and function in older adults with severe osteoarthritis [with consumer summary]. J Strength Cond Res. 2011;25(2):318-25.

113. Takacs J, Krowchuk NM, Garland SJ, Carpenter MG, Hunt MA. Dynamic balance training improves physical function in individuals with knee osteoarthritis: a pilot randomized controlled trial. Arch Phys Med Rehabil. 2017;98(8):1586-93.

114. Teirlinck CH, Luijsterburg PAJ, Dekker J, et al. Effectiveness of exercise therapy added to general practitioner care in patients with hip osteoarthritis: a pragmatic randomized controlled trial. Osteoarthr Cartil. 2016;24(1):82-90.

115. Teixeira PEP, Piva SR, Fitzgerald GK. Effects of impairmentbased exercise on performance of specific self-reported functional tasks in individuals with knee osteoarthritis. Phys Ther. 2011;91(12):1752-65.

116. Kuptniratsaikul V, Tosayanonda O, Nilganuwong S, Thamalikit$\mathrm{kul} \mathrm{V}$. The efficacy of a muscle exercise program to improve functional performance of the knee in patients with osteoarthritis. Chotmaihet Thangphaet [Journal of the Medical Association of Thailand]. 2002;85(1):33-40.

117. Thorstensson CA, Roos EM, Petersson IF, Ekdahl C. Six-week high-intensity exercise program for middle-aged patients with knee osteoarthritis: a randomized controlled trial. BMC Musculoskelet Disord. 2005;6:27.

118. Topp R, Woolley S, Hornyak J III, Khuder S, Kahaleh B. The effect of dynamic versus isometric resistance training on pain and functioning among adults with osteoarthritis of the knee. Arch Phys Med Rehabil. 2002;83(9):1187-95.

119. Topp R, Swank AM, Quesada PM, Nyland J, Malkani A. The effect of prehabilitation exercise on strength and functioning after total knee arthroplasty. PM\&R. 2009;1(8):729-35.

120. Tsauo JY, Cheng PF, Yang RS. The effects of sensorimotor training on knee proprioception and function for patients with knee osteoarthritis: a preliminary report [with consumer summary]. Clin Rehabil. 2008;22(5):448-57.

121. Vaittianadane K, Patel G, Vakhariya PM. A comparative study between the effect of agility and pertubation training versus conventional exercise in improving functional status in physically active individuals with knee osteoarthritis. Indian J Physiother Occup Ther. 2014;8(3):64-70.

122. Van Baar ME, Dekker J, Oostendorp RAB, et al. The effectiveness of exercise therapy in patients with osteoarthritis 
of the hip or knee: a randomized clinical trial. J Rheumatol. 1998;25(12):2432-9.

123. van Baar ME, Dekker J, Oostendorp RAB, Bijl D, Voorn TB, Bijlsma JWJ. Effectiveness of exercise in patients with osteoarthritis of hip or knee: nine months' follow up. Ann Rheum Dis. 2001;60(12):1123-30.

124. Wallis J, Webster K, Levinger P, Singh P, Fong C, Taylor N. A walking program for people with severe knee osteoarthritis did not reduce pain but may have benefits for cardiovascular health: a phase II randomised controlled trial. Osteoarthr Cartil. 2017;25(12):1969-79.

125. Wang T-J, Belza B, Elaine Thompson F, Whitney JD, Bennett K. Effects of aquatic exercise on flexibility, strength and aerobic fitness in adults with osteoarthritis of the hip or knee. J Adv Nurs. 2007;57(2):141-52.

126. Wang TJ, Lee SC, Liang SY, Tung HH, Wu SF, Lin YP. Comparing the efficacy of aquatic exercises and land-based exercises for patients with knee osteoarthritis. J Clin Nurs. 2011;20(17-18):2609-22.

127. Weidenhielm L, Mattsson E, Broström LA, Wersäll-Robertsson E. Effect of preoperative physiotherapy in unicompartmental prosthetic knee replacement. Scand J Rehabil Med. 1993;25(1):33-9.

128. Weng MC, Lee CL, Chen CH, et al. Effects of different stretching techniques on the outcomes of isokinetic exercise in patients with knee osteoarthritis. Kaohsiung J Med Sci. 2009;25(6):306-15.

129. Wortley M, Zhang S, Paquette M, et al. Effects of resistance and Tai Ji training on mobility and symptoms in knee osteoarthritis patients. J Sport Health Sci. 2013;2(4):209-14.

130. Koli J, Multanen J, Kujala UM, Häkkinen A, Nieminen MT, Kautiainen H, Lammentausta E, Jämsä T, Ahola R, Selänne H, Kiviranta I. Effects of exercise on patellar cartilage in women with mild knee osteoarthritis. Med Sci Sports Exercise. 2015;47(9):1767-74.

131. Corder G, Foreman D. Nonparametric statistics: an introduction. Nonparametric statistics for non-statisticians: a step-by-step approach. Hoboken: Wiley; 2009.

132. Bannuru RR, Schmid CH, Kent DM, Vaysbrot EE, Wong JB, McAlindon TE. Comparative effectiveness of pharmacologic interventions for knee osteoarthritis: a systematic review and network meta-analysis. Ann Intern Med. 2015;162(1):46-54.

133. Roddy E, Zhang W, Doherty M. Aerobic walking or strengthening exercise for osteoarthritis of the knee? A systematic review. Ann Rheum Dis. 2005;64(4):544-8.
134. Escalante Y, Saavedra JM, Garcia-Hermoso A, Silva AJ, Barbosa TM. Physical exercise and reduction of pain in adults with lower limb osteoarthritis: a systematic review. J Back Musculoskelet Rehabil. 2010;23(4):175-86.

135. Fransen M, McConnell S, Hernandez-Molina G, Reichenbach S. Exercise for osteoarthritis of the hip. Cochrane Database Syst Rev 2014;4.

136. Brosseau L, Taki J, Desjardins B, et al. The Ottawa panel clinical practice guidelines for the management of knee osteoarthritis. Part one: introduction, and mind-body exercise programs. Clin Rehabil. 2017;31(5):582-95.

137. Reid KJ, Baron KG, Lu B, Naylor E, Wolfe L, Zee PC. Aerobic exercise improves self-reported sleep and quality of life in older adults with insomnia. Sleep Med. 2010;11(9):934-40.

138. Chan JS, Ho RT, K-f Chung, et al. Qigong exercise alleviates fatigue, anxiety, and depressive symptoms, improves sleep quality, and shortens sleep latency in persons with chronic fatigue syndrome-like illness. Evid Based Complement Alternat Med. 2014;2014:106048.

139. Parmelee Patricia A, Tighe Caitlan A, Dautovich ND. Sleep disturbance in osteoarthritis: linkages with pain, disability, and depressive symptoms. Arthritis Care Res. 2014;67(3):358-65.

140. Neogi T, Felson D, Niu J, et al. Association between radiographic features of knee osteoarthritis and pain: results from two cohort studies. BMJ. 2009;339:b2844.

141. Furukawa TA, Noma H, Caldwell DM, et al. Waiting list may be a nocebo condition in psychotherapy trials: a contribution from network meta-analysis. Acta Psychiatr Scand. 2014;130(3):181-92.

142. Tanaka R, Ozawa J, Kito N, Moriyama H. Efficacy of strengthening or aerobic exercise on pain relief in people with knee osteoarthritis: a systematic review and meta-analysis of randomized controlled trials. Clin Rehabil. 2013;27(12):1059-71.

143. Bartholdy C, Juhl C, Christensen R, Lund H, Zhang W, Henriksen $\mathrm{M}$. The role of muscle strengthening in exercise therapy for knee osteoarthritis: a systematic review and meta-regression analysis of randomized trials. Semin Arthritis Rheum. 2017;47(1):9-21. 